\title{
Mechanisms underlying CD19-positive ALL relapse after anti-CD19 CAR T cell therapy and associated strategies
}

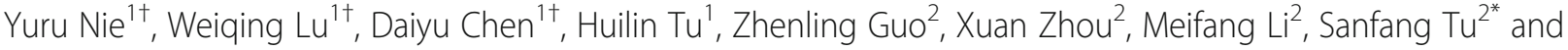 \\ Yuhua $\mathrm{Li}^{2^{*}}$ (i)
}

\begin{abstract}
Chimeric antigen receptor (CAR) T cell therapy, especially anti-CD19 CAR T cell therapy, has shown remarkable anticancer activity in patients with relapsed/refractory acute lymphoblastic leukemia, demonstrating an inspiring complete remission rate. However, with extension of the follow-up period, the limitations of this therapy have gradually emerged. Patients are at a high risk of early relapse after achieving complete remission. Although there are many studies with a primary focus on the mechanisms underlying CD19- relapse related to immune escape, early CD19+ $9^{+}$relapse owing to poor in vivo persistence and impaired efficacy accounts for a larger proportion of the high relapse rate. However, the mechanisms underlying CD19 ${ }^{+}$ relapse are still poorly understood. Herein, we discuss factors that could become obstacles to improved persistence and efficacy of CAR T cells during production, preinfusion processing, and in vivo interactions in detail. Furthermore, we propose potential strategies to overcome these barriers to achieve a reduced $\mathrm{CD} 19^{+}$relapse rate and produce prolonged survival in patients after CAR T cell therapy.
\end{abstract}

Keywords: Chimeric antigen receptor, CAR T cell therapy, Acute lymphocytic leukemia (ALL), Positive relapse, Mechanism, Strategy

\section{Introduction}

Chimeric antigen receptor (CAR) $\mathrm{T}$ cell therapy has shown revolutionary success in the field of antitumor immunotherapy [1], especially in the treatment for B cell malignancies [2, 3]. Following the first success achieved in a child with acute lymphoblastic leukemia (ALL) after infusion of anti-CD19 CAR (CD19 CAR) T cells in April 201 2[4, 5], several research institutes worldwide have reported CD19 CAR T cell therapy to be a safe and promising treatment for patients with ALL $[6,7]$. In total, $67 \%-85 \%$ of patients with ALL receiving CD19 CAR $\mathrm{T}$ cell therapy achieve complete

\footnotetext{
* Correspondence: doctortutu@163.com; liyuhua2011gz@163.com

${ }^{\dagger}$ Yuru Nie, Weiqing Lu and Daiyu Chen contributed equally to this work.

2Department of Hematology, Zhujiang Hospital, Southern Medical University, No. 253, Industrial Avenue, Guangzhou, Guangdong Province, China Full list of author information is available at the end of the article
}

remission with a negative minimal residual disease (MRD) status [8-11].

However, as more long-term follow-up data are published, a high risk of relapse after CD19 CAR T cell therapy has emerged as a nonnegligible obstacle on the road to improved efficacy and long-term survival. The relapse rate within one year could be even higher than 50\%, which indicates a large problem to be solved [12]. To date, there have been studies addressing the mechanism of resistance to CAR T cell therapy with a primary focus on issues related to $\mathrm{CD} 19$-negative $\left(\mathrm{CD}^{-} 9^{-}\right)$relapse, such as immune escape or antigen loss [13-15]. However, the CD19-positive $\left(\mathrm{CD} 19^{+}\right)$relapse rate following $\mathrm{CD} 19$ CAR T cell therapy is higher than the $\mathrm{CD}^{-} 9^{-}$relapse rate in many trials $[7,16,17]$, which can be up to $47.7 \%[12]$. Barriers to CAR $\mathrm{T}$ cell activation and expansion, limited in vivo persistence, and aberrant antileukemia activity 


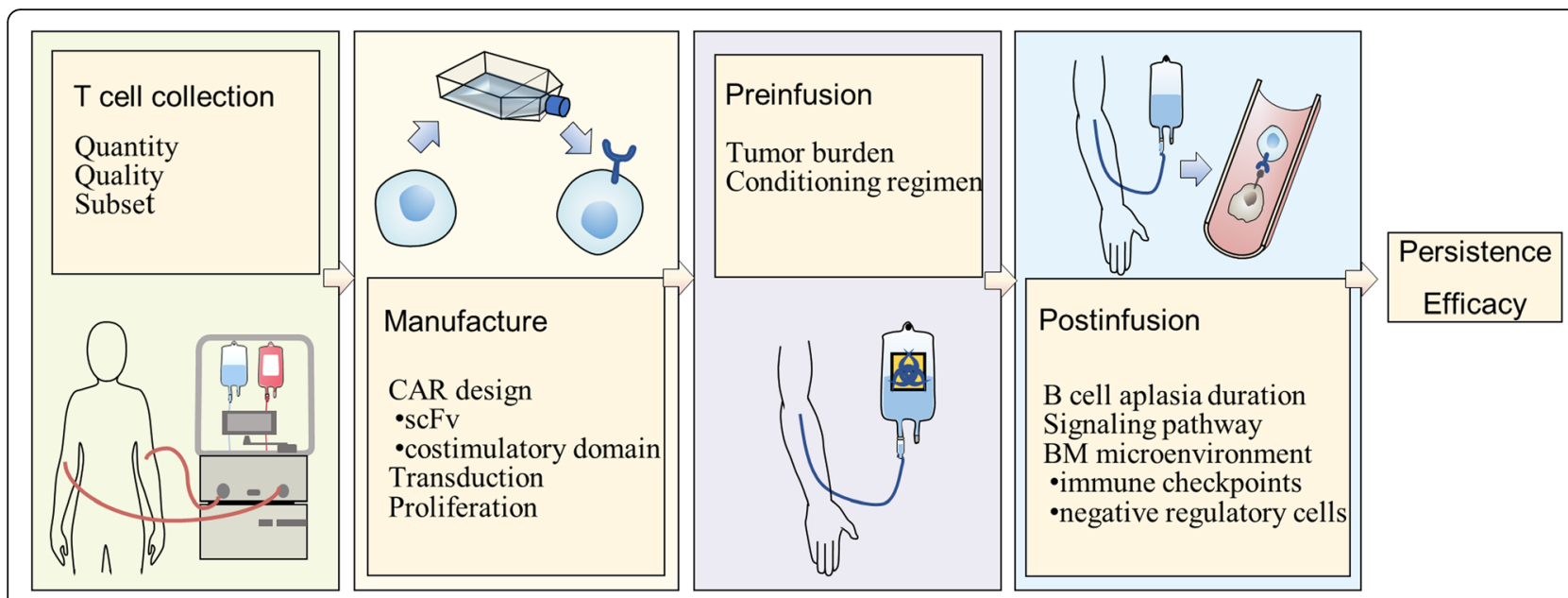

Fig. 1 Factors influencing CD19 CAR T cell therapy. The limited persistence and impaired efficacy of CAR T cells could be possible mechanisms underlying CD19+ ${ }^{+}$relapse. This figure summarizes potential obstacles to durable remission and better CAR T cell efficacy. First, T cell collection: $T$ cells selected for manufacturing should be of sufficient quantity and good quality and have a phenotype with memory characteristics. Second, CAR T cell manufacture: transgene rejection induced by a murine scFv results in transient in vivo persistence. Selection of the costimulatory domain, transduction technique, especially vector selection, and proliferation method also plays roles in persistence and efficacy. Third, preinfusion: the tumor burden before infusion is associated with patient long-term survival. In addition to lymphodepleting therapy, a conditioning regimen with fludarabine ameliorates T cell persistence. Finally, postinfusion: normal B cells are supposed to recover, but transient B cell aplasia may result in CD19 ${ }^{+}$ relapse. Aberrant signaling pathways and the BM microenvironment will impair a T cell's potential along with its in vivo persistence

are associated with an increased risk of $\mathrm{CD} 19^{+}$relapse (Fig. 1). Nonetheless, the mechanisms underlying CD19 relapse are still poorly elucidated.

In this review, we discuss the clinical status of CD19 CAR $\mathrm{T}$ cell therapy for ALL, analyzing possible clinical factors for $\mathrm{CD} 19^{+}$relapse prediction and/or intervention. Furthermore, we summarize knowledge related to mechanisms underlying $\mathrm{CD}_{1}{ }^{+}$relapse in detail and propose feasible strategies to overcome barriers to durable remission.

\section{Clinical analysis of CD19-positive ALL relapse after CD19 CAR T cell therapy} Importance of CAR T cell persistence

A lack of in vivo CD19 CAR T cell persistence is an important causative factor of $\mathrm{CD}^{+} 9^{+}$relapse after CAR $\mathrm{T}$ cell therapy for ALL [18]. Turtle CJ et al. found that $\mathrm{CD} 19^{+}$recurrence occurred exclusively in patients without persistent CAR T cells [17]. Three patients were observed to have $\mathrm{CD} 19^{+}$relapse after early loss of CAR $\mathrm{T}$ cells, while another three patients whose CAR T cells remained experienced $\mathrm{CD}^{-} 9^{-}$recurrences [11]. The long-term survival of CAR $\mathrm{T}$ cells enables continuous surveillance and ongoing clearance of $\mathrm{CD} 19^{+}$leukemia cells. Once the CAR T cell frequency diminishes to an undetectable level, abnormal $\mathrm{CD} 19^{+} \mathrm{B}$ cells are likely to repopulate, resulting in antigen-positive relapse.

\section{Duration of B cell aplasia}

Early $\mathrm{CD} 19^{+}$relapse is associated with not only limited CAR $\mathrm{T}$ persistence but also transient $\mathrm{B}$ cell aplasia [6].
Actually, the relatively high expansion peak and prolonged duration of CAR T cells account for delayed B cell recovery in the context of a relatively strong and prolonged cytokine-mediated toxicity profile [19]. According to Maude SL and colleagues' trial, relapse was heralded by recovery of $\mathrm{CD} 19^{+} \mathrm{B}$ cells in two patients who experienced CD19 CAR T cell loss, while nineteen patients with longer remission were observed to have a longer duration of B cell aplasia [11]. Qian C also found that six subjects developed $\mathrm{CD} 19^{+}$relapse following $\mathrm{B}$ cell recovery at 2 to 4 months after infusion [20]. Therefore, a relatively limited duration of B cell aplasia is related to an increased $\mathrm{CD} 19^{+}$relapse risk, suggesting that monitoring for the return of $\mathrm{B}$ cells will be a useful method for predicting ALL relapse and providing a window for consolidation treatment $[7,11]$.

\section{Selection of the costimulatory domain}

It has been revealed that CAR $T$ cells with $4-1 B B$ as a costimulatory domain $(\mathrm{CD} 19-\mathrm{BB} \zeta)$ have better persistence than those with $\mathrm{CD} 28$ as a costimulatory domain (CD19-28 $)$ [21, 22]. Whether the same result is found in clinical practice remains unclear. In current clinical trials of CD19 CAR T cell therapy for ALL, CD19-28 CAR $T$ cells can exist in vivo for a median time of 3 months, with almost 7 months as the longest duration [23], while $\mathrm{CD} 19-\mathrm{BB} \zeta \mathrm{CAR} \mathrm{T}$ cells have a persistence of up to 20 months [6] and $68 \%$ in vivo survival over 6 months in patients [11]. The median $\mathrm{CD} 19^{+}$relapse rates of $\mathrm{CD} 19-\mathrm{BB} \zeta$ and $\mathrm{CD} 19-28 \zeta \mathrm{CAR} \mathrm{T}$ cells are $16.7 \%$ 
and $22.7 \%$, respectively, and the maximums are $31.1 \%$ and $47.7 \%$ (See Table 1). It appears that patients infused with CD19-BB $\zeta$ CAR T cells have better CAR $T$ cell persistence and a lower $\mathrm{CD} 19^{+}$relapse rate than those infused with CD19-28 C CAR T cells. However, the trials studying these cells have all been single-armed trials, which lack credibility and statistical significance in comparisons.

Cheng $\mathrm{Z}$ et al. performed a study to observe the differences in expansion kinetics, persistence and clinical effects between two kinds of CAR $\mathrm{T}$ cells in the same patient. The results showed no significant differences but varied significantly among different patients, suggesting the need for a patient-specific CAR construction design [24] . Qian C et al also carried out a trial to compare these two CAR design options and showed no significant differences. However, positive results were achieved in their subsequent study after they modified the manufacturing method [20]. Therefore, we should treat the problem of costimulatory domain selection relatively cautiously and still need additional randomized controlled clinical trials for verification.

\section{Consideration of the tumor burden}

The tumor burden prior to conditioning regimen administration cannot be excluded from consideration in the clinical application of CAR T cell therapy and plays a role in the relapse of $\mathrm{CD} 19^{+}$disease. When stimulated by an increased level of target cells, $\mathrm{T}$ cells are more rapidly cleared from the circulation and more likely to be inactivated $[9,25]$. Furthermore, overexposure to $\mathrm{CD} 19^{+}$ target cells can rapidly internalize the CAR on the surface of CAR T cells, which results in damage to the antitumor effect of the CAR T cells [26]. Park J H et al. demonstrated that the preinfusion leukemia load was a good indicator to predict long-term remission duration and the survival rate [12]. The tumor burden was negatively correlated with CAR T cell persistence $[12,25]$. It is relatively clear that patients with relatively high levels of leukemia blasts are prone to developing more severe cytokine release syndrome (CRS), for which high-dose steroid therapy is used [12, 18, 27]. However, as cytotoxic drugs, steroids presumably have a negative impact on $\mathrm{T}$ cell potential. During a clinical trial, three patients experienced $\mathrm{CD} 19^{+}$relapse after administration of highdose steroids because of their severe CRS resulting from their relatively high leukemia burdens [8, 19]. Thus, tumor load reduction helps to avoid overloaded cytokine storm and induce long-term durable remission. Nevertheless, to produce necessary antitumor efficacy, CAR $\mathrm{T}$ cells still require a certain number of target cells for activation and expansion [23]. The balance among the tumor load, CRS, T cell potency and persistence should be seriously considered and controlled.

\section{Anti-CD19 CAR T cell therapy for different subtypes of ALL}

Since there are different ALL subtypes with typical cytogenetic signature respectively, CAR $\mathrm{T}$ cell therapy may show different outcomes in patients with certain subtypes. Philadelphia chromosome-positive $(\mathrm{Ph}+)$ ALL which associated with aggressive clinical outcome and poor prognosis accounts for approximately $30 \%$ of cases of adult ALL [28]. In Davila, M. L.'s trial, CAR T cell therapy was as effective in the $4 \mathrm{Ph}+$ patients as in the others with relapsed CD19+ ALL after hematopoietic stem cell transplantation (HSCT )[8]. According to another trial in which authors compared outcomes of antiCD19 CAR T cell therapy between ALL patients with and without $\mathrm{Ph}+$ status, confidence intervals for the differential response rates showed that observed proportion of patients with $\mathrm{Ph}+$ status appeared to be higher than that of patients without $\mathrm{Ph}+$ status, even though these results did not reach statistical significance. However, $\mathrm{Ph}+$ status was proved to have nothing to do with the overall survival in this trial [12].

Genome-wide and other molecular techniques have resulted in the identification of a distinct group of patients with a previously unknown subtype: Philadelphialike (Ph-like) ALL, which has higher frequency and shorter 5-year survival [28]. Although this genotype is $\mathrm{Ph}$-negative, it has a similar gene expression profile to that of Ph+ ALL but embraces a highly diverse range of genetic alterations activating kinase signaling [29]. Since Ph-like ALL has aberrations affecting critical pathways such as Ras, JAK-STAT [30], and PI3K/AKT/mTOR(6), CAR T cells' efficacy may be impaired after infusion which will induce a higher risk of disease relapse [32, 33]. Hypodiploid ALL, another subtype, was also recently proved to show activation of Ras and PI3K pathways [34]. However, preclinical and clinical studies concerning CAR $\mathrm{T}$ cell therapy for these subtypes are still lacking. Whether ALL patients of different subtypes treated by CAR $\mathrm{T}$ cell therapy will achieve consistent remission rate and duration still remain to be determined conclusively.

\section{Predictive factors for positive relapse in clinical practice}

During clinical practice, some factors can be used to predict long-term survival and the possibility of relapse. An elevated prelymphodepletion platelet count, a reduced prelymphodepletion lactate dehydrogenase concentration, a lymphodepletion regimen combined with fludarabine, and no evidence of extramedullary disease or high-risk cytogenetics are associated with better event-free survival. Patients with a relatively high frequency of marrow blasts, decreased persistence of B cell aplasia, or changes in distinct serum cytokines are at an elevated risk of $\mathrm{CD}_{1}{ }^{+}$relapse $[7,9,35,36]$. Age, 


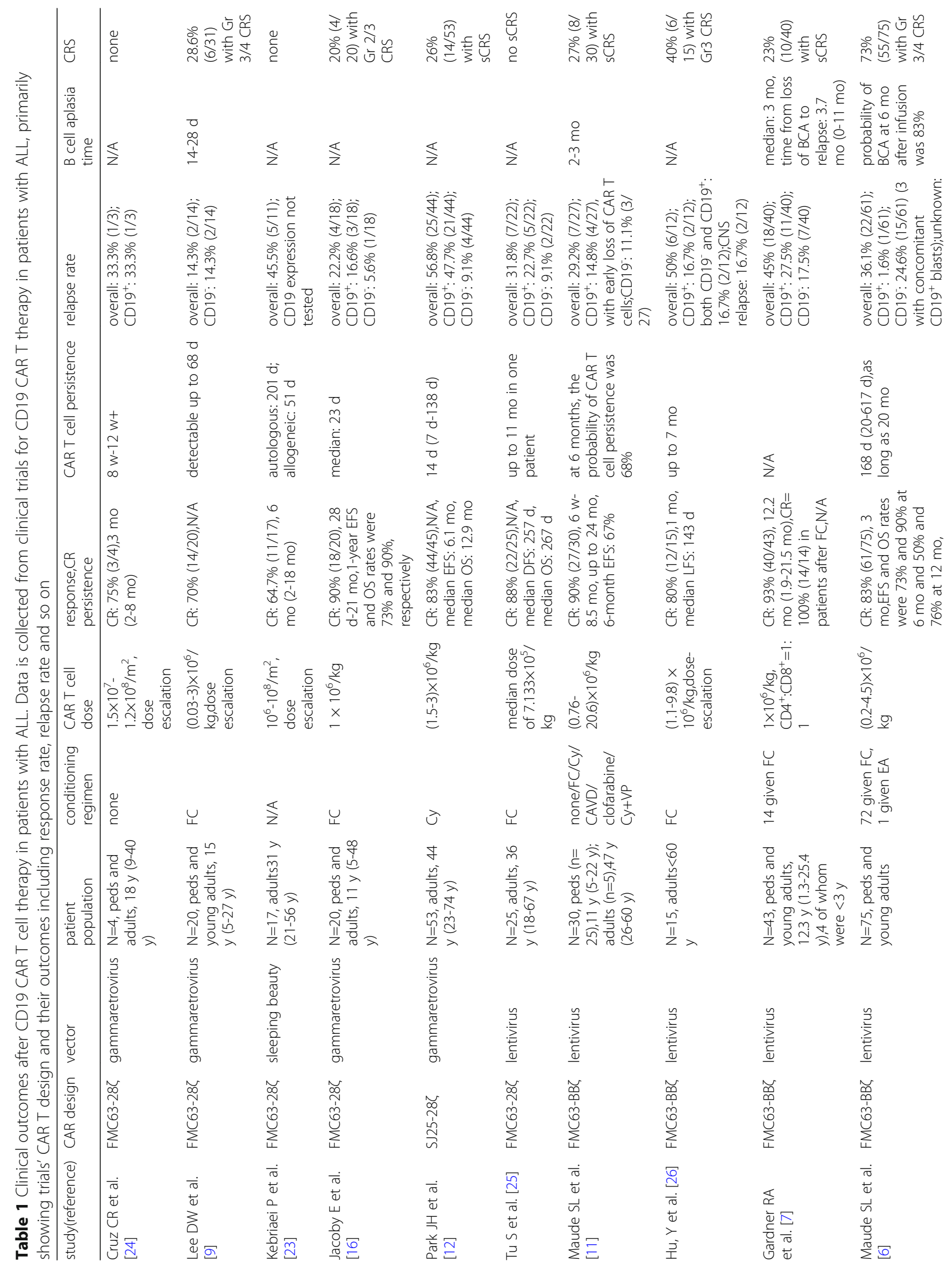




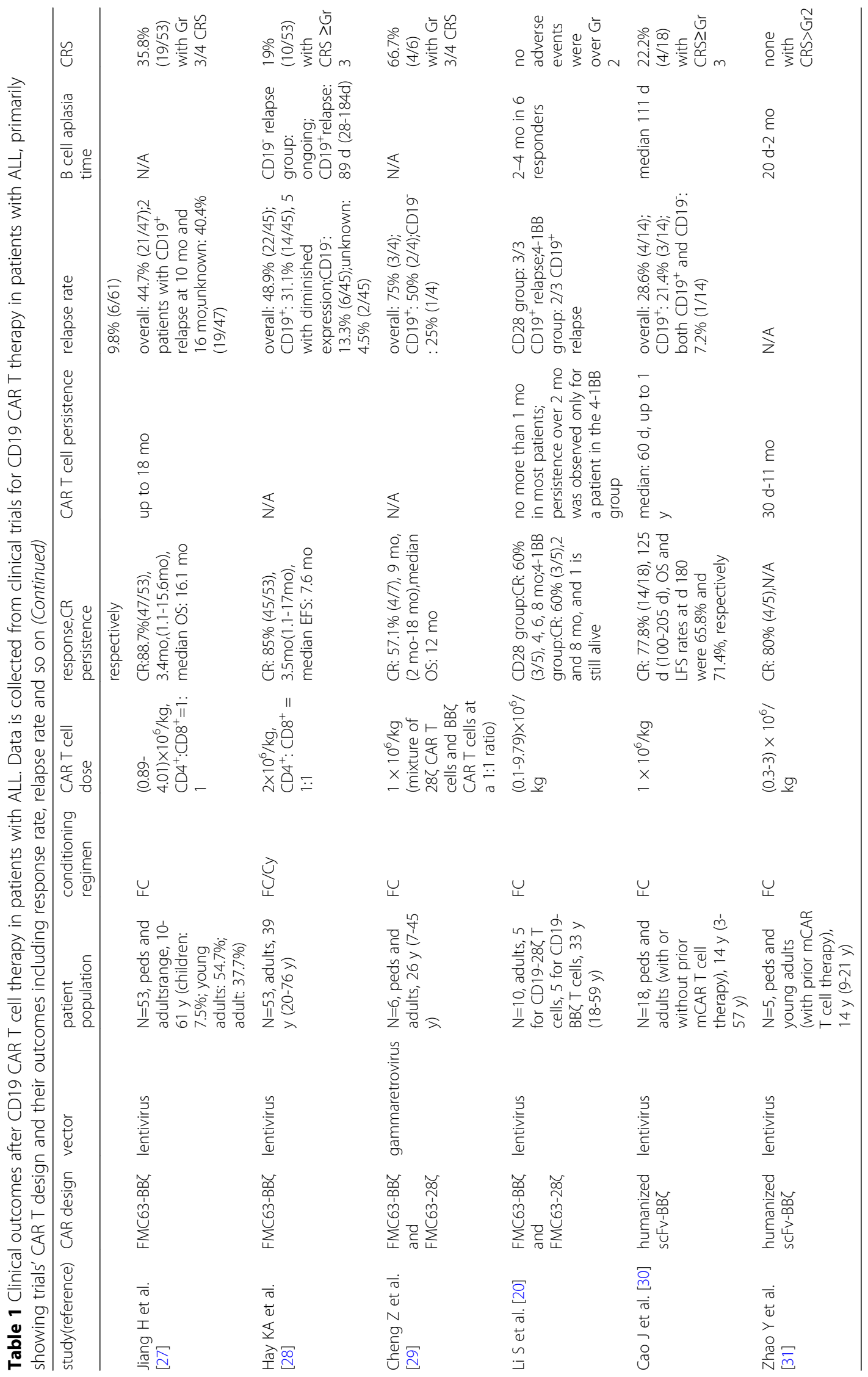


performance status, previous allogeneic hematopoietic stem cell transplantation (HSCT) or blinatumomab treatment and the dose of infused CAR $\mathrm{T}$ cells did not show any significant effects on long-term survival [23, 35]. However, in a clinical trial carried out in our department, we found that elderly patients were at an increased risk of disease relapse or progression, which requires a further study to confirm the relation between age and relapse risk [37].

\section{Mechanism of $\mathrm{CD} 19^{+}$relapse Manufacture of CAR T cells in vitro $T$ cells are insufficient in quantity and poor in quality}

To manufacture CAR $\mathrm{T}$ cells requires collecting enough good-quality $\mathrm{T}$ cells. Due to previous cytotoxic therapy, patients often develop lymphopenia, preventing the harvest of adequate amounts of $\mathrm{T}$ cells for CAR $\mathrm{T}$ cell therapy. Furthermore, it has been observed that chemotherapeutic regimens containing clofarabine or doxorubicin are associated with an insufficient quantity or poor quality of CAR $\mathrm{T}$ cell products [9]. Moreover, clinical data suggest that previous treatment with cyclophosphamide and cytarabine can selectively reduce the frequency of early-lineage $\mathrm{T}$ cells associated with CAR T cell expansion [38].

Prior treatments before CAR T cell therapy, such as chemotherapy, can affect the quality of the T cells collected. Multiple chemotherapies affect the metabolic pathways of $\mathrm{T}$ cells in vivo, thereby affecting the quality and persistence of CAR T cells [39] .

\section{CAR $T$ cell products generated from different $T$ cell subsets have different potencies}

At present, the $\mathrm{T}$ cell subsets used for CAR T cell manufacture are not strictly defined [40], so CAR T cell products are composed of $\mathrm{CD}^{+}$and $\mathrm{CD} 8^{+} \mathrm{T}$ cells with an activated effector $T\left(T_{E}\right)$ cell phenotype [2]. Naïve $T$ $\left(\mathrm{T}_{\mathrm{N}}\right)$ cells can differentiate into $\mathrm{T}$ memory stem $\left(\mathrm{T}_{\mathrm{SCM}}\right)$ cells, central memory $\mathrm{T}\left(\mathrm{T}_{\mathrm{CM}}\right)$ cells and effector memory $\mathrm{T}\left(\mathrm{T}_{\mathrm{EM}}\right)$ cells, with the lifespan gradually shortening and the self-renewal ability weakening [40, 41]. However, $\mathrm{T}_{\mathrm{EM}}$ and $\mathrm{T}_{\mathrm{E}}$ cells used for adoptive immunotherapy have poor proliferative and survival abilities, which can lead to relapse [41].

\section{Construction of a CAR}

Murine single-chain variable fragments (scFvs) induce an immune response At present, most CAR T cell products, especially scFvs, used in clinical trials are derived from mice (FMC63 [42] or SJ25C1-mAb), which could induce immunological rejection in vivo, particularly via $\mathrm{CD}^{+} \mathrm{T}$ cell-mediated immune responses [43]. In a clinical trial, Cameron J. Turtle et al .[17] found that there was no expansion or persistence of CAR $\mathrm{T}$ cells in
5 of 6 patients with $\mathrm{CD} 19^{+}$relapse when the authors reinfused the products after relapse and an immune response to the CAR transgene product was found in all of the patients. When CAR T cells were used for other solid tumors, there were different degrees of immune rejection as well [44-47]. Moreover, tonic signaling from murine CAR T cell clusters of CAR molecules results in the exhaustion of CAR T cells [17]. Therefore, reinfusion of CAR $\mathrm{T}$ cells into patients with $\mathrm{CD} 19^{+}$relapse after mouse CAR $\mathrm{T}$ cell infusion is generally ineffective.

Selection of a costimulatory domain Second-generation CAR T cells containing a CD3 3 signaling domain coupled with another costimulatory molecule exhibit improved proliferation and function. CD28 and 4-1BB are the two costimulatory domain options used in most preclinical and clinical studies. 1. CAR $\mathrm{T}$ cell inhibition induced by $\mathrm{T}$ regulatory cells (Tregs) and the immunosuppressive molecules IL-10 and TGF- $\beta$ can be reduced by the corporation of the CD28 domain [48]. 2. CD19-28 $\mathrm{T}$ cells are also able to induce an augmented antitumor response and increased proliferation via enhanced activation of the transcription factor NF- $\mathrm{kB}$, which helps to promote cytokine gene transcription and secretion [49]. 3. It has been confirmed that CD19-28 $\mathrm{T}$ cells show a strong functional potential and high expansion but expansion was subsequently followed by relatively rapid exhaustion after tonic $\mathrm{CAR} \mathrm{CD} 3 \zeta$ phosphorylation triggered by clustering of a CAR scFv [21]. Since CD19-28 $\mathrm{T}$ cells produce a robust antileukemia response and exhibit increased cytokine secretion, patients infused with these cells are relatively likely to develop severe CRS and need steroid therapy. However, high doses of lymphotoxic steroids limit the proliferation and persistence of CD19-28z CAR T cells and lead to recurrence while tocilizumab does not, which the specific mechanism remains unknown $[8,19]$. Therefore, CD19-28ᄃ $\mathrm{T}$ cells can mediate rapid remission, but the risk of relapse will be high, remaining unfavorable for long-term survival (Fig. 2a)

$\mathrm{CD} 19-\mathrm{BB} \zeta \mathrm{T}$ cells have a high mitochondrial respiration capacity, providing increased oxidative metabolism and differentiation into central memory $\mathrm{T}\left(\mathrm{T}_{\mathrm{CM}}\right)$ cells [50, 51]. 4-1BB domain signaling can also activate the AKT/mammalian target of rapamycin pathway and upregulate the expression of the antiapoptotic genes $\mathrm{Bcl}-\mathrm{xL}$ and BFL-1, which is beneficial to $\mathrm{T}$ cell survival and proliferation [22]. In contrast to CD19-28 $\mathrm{T}$ cells, CD19$\mathrm{BB} \zeta \mathrm{T}$ cells have better persistence with diminished expression of exhaustion-associated molecules obtained by a stronger response to hypoxia, upregulated cellular metabolism and negative regulation of apoptosis [21].

Although $\mathrm{CD} 19-\mathrm{BB} \zeta \mathrm{T}$ cells are related to prolonged persistence, their duration in vivo is still limited because of certain mechanisms of self-death. When using a gamma retroviral vector, tonic CAR-derived 4-1BB 


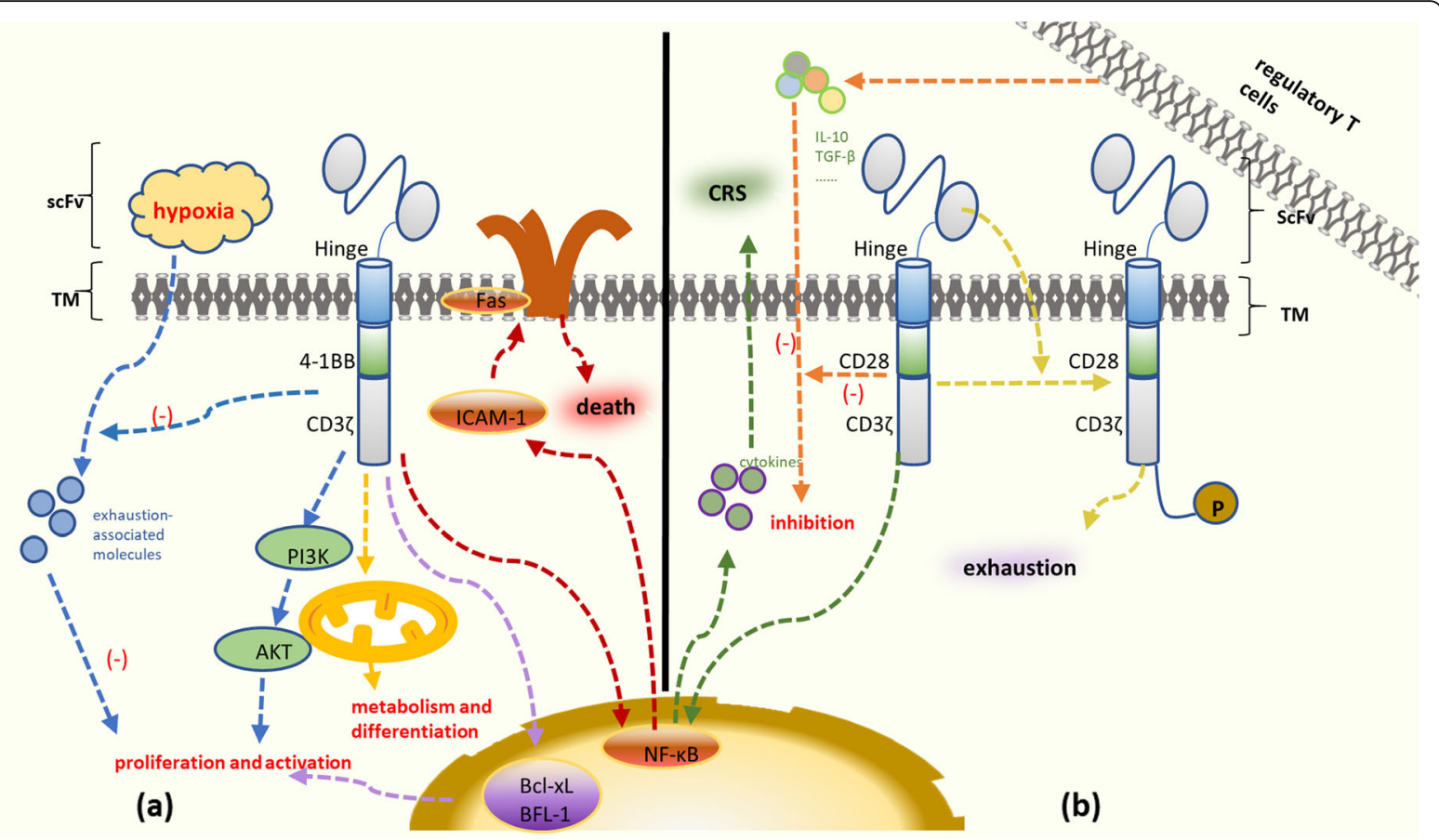

Fig. 2 Main signaling pathways involved in CD19-BBC T cells and CD19-28Z T cells. a A high mitochondrial respiratory capacity promotes metabolism and differentiation. 4-1BB domain signaling activates the PI3K pathway and upregulates BCl-xL and BFL-1 expression. Tonic CAR-derived 4-1BB signaling activates the NF-B pathway and enhances FAS-dependent apoptosis. CD19-BBC T cells diminish the expression of exhaustion-associated molecules more than CD19-28 T cells. b The main signaling pathways involved in CD19-28 $T$ T cells. CAR T cell inhibition induced by regulatory T cells, IL-10 and TGF- $\beta$ can be reduced by the incorporation of the CD28 domain. CD19-28乙 T cells exhibit enhanced activation of the transcription factor NF$B$ and promote cytokine secretion. CD19-28Z T cells are more likely to result in the development of severe CRS than CD19-BBZ T cells. However, tonic CAR CD3 , phosphorylation triggered by clustering of the CAR single-chain variable fragment (scFv) leads to more rapid exhaustion

signaling persistently activates the NF- $\mathrm{B}$ pathway via tumor necrosis factor receptor-associated factor 2 (TRAF2), which upregulates the expression of intracellular adhesion molecule 1 (ICAM-1) and enhances FASdependent apoptosis [52, 53] (Fig. 2b)

In addition to $\mathrm{CD} 28$ and $4-1 \mathrm{BB}$, other costimulatory domains such as OX40 and ICOS also have potential to induce persistence and antitumor responses, which has been revealed in preclinical studies [54, 55]. Moreover, Toll-like receptors (TLRs) play an important role in the immune response. It has been showed that after induction chemotherapy, the mRNA expression of TLR2 was significantly lower as compared to before treatment [56]. There are many other costimulatory domains, such as Dap10 costimulatory domains, 2B4 costimulatory domains, GITR domains, CD150 signaling lymphocytic activation molecule (SLAM), a $150-\mathrm{kDa}$ protein termed as M150. Different costimulatory domain induces differential effects in CAR-expressing T cells [57-61].

\section{Expansion of CAR T cells in vitro}

Matthew E. Pipkin et al. suggested that strong IL-2 signaling had a negative impact on $\mathrm{CD}^{+} \mathrm{T}$ cell memory formation but did not influence secondary expansion.
IL-2 could also promote effector cytotoxic T lymphocyte (CTL) differentiation and senescence [62]. A metaregression analysis article analyzed the relationship between "adding IL-2 during cell culture" and the overall response rate (ORR) of cultured CAR $\mathrm{T}$ cells. The results of the analysis showed that the cells cultured without the addition of IL-2 had a higher ORR than those cultured with IL-2 [63]. The ORR of CAR T cells can result in a worse effect, which leads to relapse.

\section{Transfection can lead to CAR T cell recurrence}

Virus-based vectors are the most commonly used gene delivery system. Studies have shown that retrovirus transfection of $\mathrm{T}$ cells introduces vector-derived immunogenic epitopes into patient' $\mathrm{T}$ cells. Therefore, anti-CAR $\mathrm{T}$ cells produced in patients target both the CAR vector and retroviral vector epitopes. As a result, CAR $\mathrm{T}$ cells are likely to be identified and attacked in vivo, CAR $\mathrm{T}$ cell persistence is reduced, and recurrence occurs [45].

Another important side effect of CD19 CAR T cell therapy is B cell hypoplasia. Due to the integrability of lentiviral vectors (LVs) and the persistence of $\mathrm{T}$ cell clones after adoptive transfer, LV-modified $\mathrm{T}$ cells 
appear to be able to persist for $>5$ years after treatment and continue to induce $\mathrm{B}$ cell hypoplasia, which may lead to recurrence [64].

Virus-based vectors also have other potential safety problems. They can integrate semirandomly into the human genome, which can lead to insertional mutagenesis and make the engineered cells become tumorigenic [65]

In recent years, the most widely used transposon is the sleeping beauty (SB) transposon system. Although the efficiency of SB-mediated stable gene transfer is significantly higher than that of conventional DNA-mediated random integration, because SB inserts randomly, there are still many questions about safety in clinical applications [66].

CRISPR/Cas9 technology originates from type II CRISPR/Cas9 systems. However, CRISPR/CAS9 gene editing induces off-target cleavage events in therapeutic applications depending on the experimental environment and cell type. Therefore, the problem we need to consider is to what extent these nucleases induce offtarget cleavage events [67].

\section{Aberrant signal transduction pathways}

The limited in vivo persistence, cytotoxicity and expansion of CAR T cells could also be due to aberrant signaling pathways within CAR $\mathrm{T}$ cells or interactions between CAR $\mathrm{T}$ cells and tumor cells.

BCR-activated signal transduction pathways, such as the PI3K/AKT/mTOR and JAK2/STAT signaling pathways, are related to CAR T cell potency. Zheng W et al. demonstrated that tonic signaling through CAR CD3 $\zeta$ ITAMs led to activation of PI3K signaling and was associated with a more differentiated phenotype [32]. In contrast, $\mathrm{T}$ cells with a less differentiated phenotype, such as TCM and TSCM cells, are associated with increased persistence and improved antitumor reactivity and expansion. Urak R and colleagues also described the correlations between PI3K/AKT/mTOR signaling inhibition and CAR $\mathrm{T}$ cell populations with memory-like characteristics that have prolonged persistence and comparatively high antitumor activity [68]. In addition, JAK2 genetic mutation has been observed in many hematological malignancies. IL-6/JAK/STAT3 signaling acts to drive the proliferation, survival, invasiveness, and metastasis of tumor cells, inducing upregulation of the expression of the immune checkpoint molecules PD-1 and/or PD-L1 and thus suppressing the immune response, which impairs the function of CAR T cells [33].

Abnormalities in the apoptotic pathway employed by CD19 CAR T cells are thought to be another mechanism underlying impaired CAR T cell cytotoxicity. Tumor necrosis factor-related apoptosis-inducing ligand (TRAIL) apoptotic pathway-mediated killing is the principle pathway through which CD19 CAR T cells induce tumor cell apoptosis [69]. Cross-resistance to TRAIL results from downregulated expression of death receptor-5 (DR-5), which leads to dysfunction in CD19 CAR T cells [70].

The cGAS-STING signaling pathway can be activated by dsDNA released during tumor cell division. Downregulation of cGAS-STING signaling leads to less type I interferon (IFN), which plays important roles in the antitumor response and prevention of $\mathrm{T}$ cell apoptosis [71]. Moreover, tumor cells can produce adenosine to suppress the antitumor ability of CD19CAR $\mathrm{T}$ cells via the adenosine receptor 2A signaling (A2Ars) pathway [72].

\section{Bone marrow (BM) microenvironment}

It has been reported that the tumor microenvironment leads to relapse via immunosuppression, mostly in solid tumors. However, studies on the role of the BM microenvironment in ALL relapse have not been published. Here, we inferred the mechanism of relapse in the BM microenvironment based on other leukemias treated with CAR T cell therapy (Fig. 3).

\section{Suppressive regulatory cells inhibit the immune function of the BM microenvironment}

Tregs inhibit normal immune cells in the tumor microenvironment, allowing tumor cells to exist [73] primarily via four mechanisms: (1) induction of $\mathrm{T}$ cell apoptosis via cell-cell interactions; (2) inhibition of immune responses by cytokine secretion; (3) release of perforin and granzymes to kill CTLs, monocytes and DCs directly; and (4) suppression of local immune responses through expression of cytotoxic T-lymphocyte-associated protein 4 (CTLA-4) [74-76]. Furthermore, IL-2, IL-7, IL-10 and TGF- $\beta$ have been proven to lead to the recruitment, differentiation and expansion of Tregs [75].

It has been observed that myeloid-derived suppressor cells (MDSCs) inhibit human CAR $\mathrm{T}$ cell responses in tumors, including the CD19 CAR $\mathrm{T}$ cell response in lymphoma [77-79]. MDSCs inhibit $\mathrm{T}$ cells via seven mechanisms: (1) inhibition of the proliferation and activation of $\mathrm{CD}^{+}$and $\mathrm{CD}^{+} \mathrm{T}$ lymphocytes through arginase- 1 or nitrogen oxide synthase 2 as well as IDO; (2) alteration of the macrophage phenotype toward a type 2 response and associated activity by increasing the IL-10 level; (3) inhibition of the cytotoxicity, natural killer group 2D (NKG2D) expression, and IFN-gamma production of natural killer (NK) cells; (4) induction of Tregs; (5) upregulation of PD-1 expression on MDSCs via hypoxia-inducible factor- $1 \alpha$; (6) deregulation of Fasmediated apoptosis; and (7) establishment of immunosuppression via the GM-CSF/JAK2/STAT3 pathway [77-82]. 


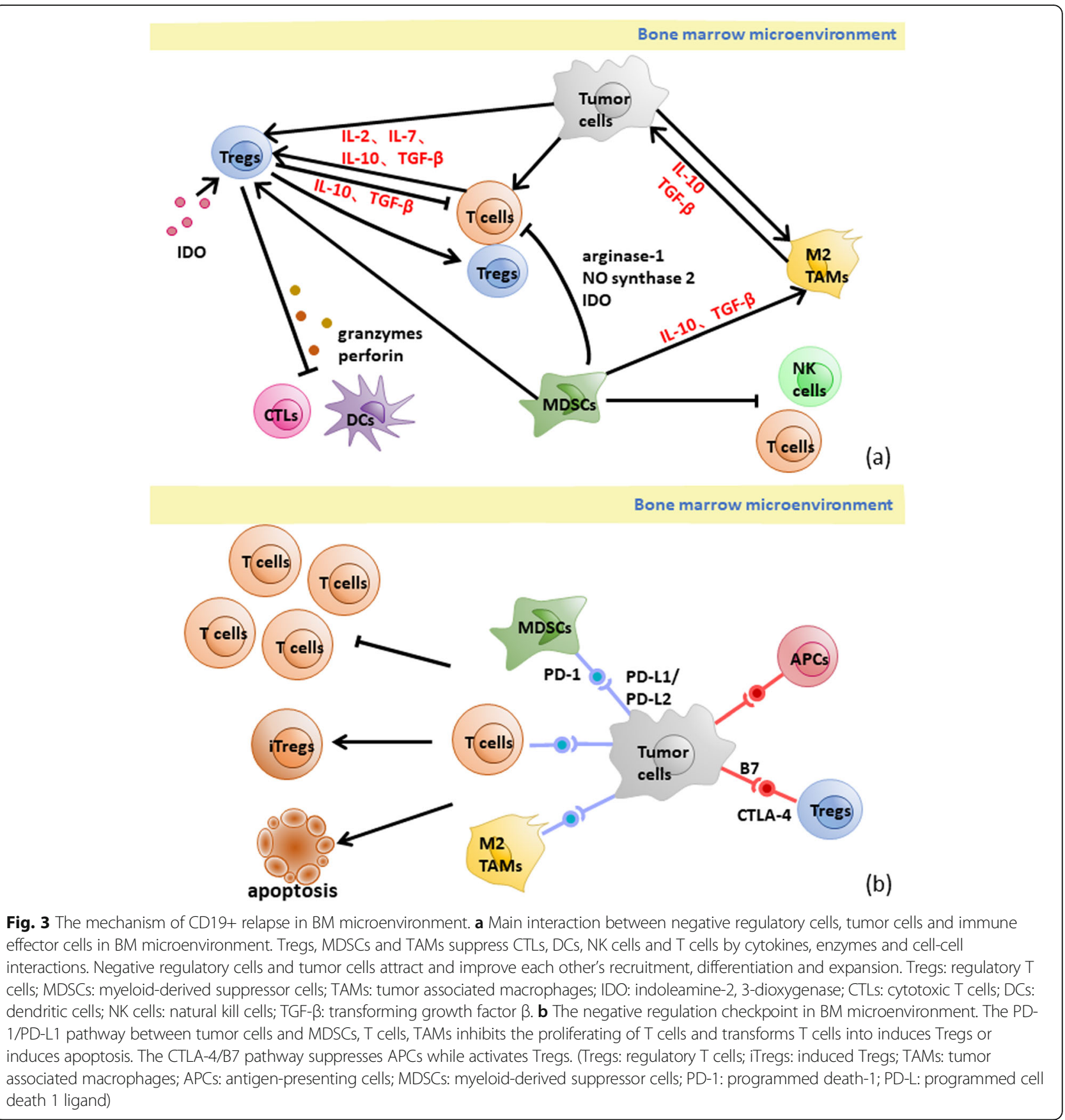

Tumor-associated macrophages (TAMs) are recruited by tumor cells via cytokines such as CSF-1 and IL-10 and converted into M2 macrophages [83], which have anti-inflammatory, angiogenic and tumor-promotive effects [74]. TAMs attract chronic lymphocytic leukemia (CLL) cells by secreting CXCL12 and CXCL13 and protect CLL cells from spontaneous or drug-induced apoptosis via CXCL12, BAFF, APRIL, CD31, and Plexin-B1 and activating the BCR signaling cascade [84].

\section{Suppressive immune checkpoints inhibit the activation of T cells}

Like CD28, CTLA-4, which is expressed on antigenpresenting cells (APCs), has B7 ligands (CD80 and CD86), which have been shown to exhibit upregulated expression in acute myelocytic leukemia (AML) cells [85], and the affinity of CTLA-4 for the B7 ligands is higher than that of CD2 8[86]. Once bound to a B7 molecule, CTLA-4 downregulates TCR activation by competing for $\mathrm{CD} 28$ and 
initiating suppressive signals at the same time, which are involved in the negative regulation of the immune response. However, CTLA-4 is constitutively expressed on Tregs and provides activation signals to these cells $[81,85]$.

It has been reported that the expression of PD-L1 and/or PD-L2 in many AML cells can be further upregulated in the presence of activated $\mathrm{T}$ cells, including CAR $\mathrm{T}$ cells, mainly through the production of IFN- $\gamma[81,85]$. The PD-1/PD-L1 pathway modulates immunosuppression primarily via the following mechanisms: (1) binding of PD-L1 on the surface of tumor cells, TAMs or MDSCs with PD-1 on the surface of tumor-specific T cells to induce apoptosis and depletion of tumorinfiltrating lymphocytes in the tumor microenvironment; (2) preventing $\mathrm{T}$ cells from proliferating by selectively inhibiting the RAS/ MEK/ERK and PI3K/AKT signaling pathways, accordingly blocking cell cycle-related gene transcription and protein expression; and (3) promoting the transformation of $\mathrm{CD}^{+} \mathrm{T}$ cells into induced Tregs (iTregs) through PD-L1 expressed on APCs [81].

In addition, IDO is highly expressed in the microenvironments of various tumors and shows high protein expression in the peripheral lymphoid organs (the lymph nodes, spleen and tonsils [87]. Overexpression of IDO promotes immune tolerance mainly through the production of kynurenine, which can inhibit the proliferation and differentiation of $\mathrm{CD}^{+} \mathrm{T}$ cells, activate aromatic receptors and promote the differentiation of Tregs, resulting in the inhibition of the antitumor immune response $[81,85,88,89]$.

\section{Strategies}

\section{Sufficient quantity of high-quality $T$ cells}

The manufacturing of a CAR $\mathrm{T}$ cell product is feasible with a $\mathrm{CD}^{+}$cell count of $\geq 150$ cells/ $\mu$ l [14]. Furthermore, collecting $\mathrm{T}$ cells from patients at a high risk of recurrence early or before treatment may improve the quality of the produced CAR T cells [14]. To avoid the toxic effects of multiple chemotherapies on cells, we can reduce the frequency of chemotherapy and increase the interval time. Additionally, creating CAR T cell product from healthy donor cells is an alternative strategy to avoid poor CAR $\mathrm{T}$ cell quality. Currently, several research groups are testing donor-based CAR $\mathrm{T}$ cell therapeutic strategies in the contexts of clinical $[90,91]$ and posttransplant relapses in patients who can be treated with $\mathrm{T}$ cells derived directly from the original allogeneic stem cell donors. The results show only a low frequency of high-grade graft-versus-host disease (GVHD) [92-94].

\section{Selective manufacture of CAR T cells from the memory stem cell subset}

Selecting the memory stem cell subset can improve the persistence and efficiency of CAR $\mathrm{T}$ cells. $\mathrm{T}_{\mathrm{SCM}}$ cells defined as
$\mathrm{CD} 6 \mathrm{~L}^{+} \mathrm{CCR} 7{ }^{+} \mathrm{CD} 45 \mathrm{RA}^{+} \mathrm{CD} 95^{+} \mathrm{CD} 45 \mathrm{RO}^{-} \mathrm{CD} 28^{+} \mathrm{CD} 27^{+} \mathrm{IL}$ $2 \mathrm{Rb}^{+} \mathrm{IL} 7 \mathrm{R}^{+}$cells not only have stem cell-like properties, including the abilities of self-renewal and multipotency, but can also differentiate into $\mathrm{T}_{\mathrm{CM}}$ and $\mathrm{T}_{\mathrm{EM}}$ cells in vitro, which have enhanced properties of self-renewal, proliferation and survival [41, 95] (Fig. 4a). Researchers analyzed the distributions of $\mathrm{T}$ cell subsets in the peripheral blood from 92 healthy subjects ranging from 3 to 88 years old and found that $\mathrm{T}_{\mathrm{SCM}}$ cells accounted for $1.27 \pm 0.55 \%$ of the $\mathrm{CD}^{+}$and $0.98 \pm 0.53 \%$ of the $\mathrm{CD}^{+} \mathrm{T}$ cell populations and that the absolute number of $\mathrm{CD} 8^{+} \mathrm{T}_{\mathrm{SCM}}$ cells decreased with age, while the number of $\mathrm{CD}^{+} \mathrm{T}_{\mathrm{SCM}}$ cells was stable [96].

There is an experiment showing that CD19 CARmodified $\mathrm{T}_{\mathrm{SCM}}$ cells have enhanced metabolic fitness and mediate robust long-lasting antitumor responses [42]. In a clinical trial by Franziska Blaeschke et al. [97] that included 4 pediatric ALL patients, CAR T cell products consisting mostly of $\mathrm{T}_{\mathrm{CM}}$ and $\mathrm{T}_{\mathrm{SCM}}$ cells had excellent proliferative and antitumor capabilities in vivo. Moreover, the products created with the protocol chosen in the trial expressed rather low levels of inhibitory checkpoint molecules on the cell surface, which indicated their persistence and high efficiency [97]. A clinical trial by Joseph A. Fraietta et al. showed that the median frequency of $\mathrm{T}_{\mathrm{SCM}}$ cells in CAR $\mathrm{T}$ cells products was modestly high in complete remission patients [43]. Therefore, selecting a memory stem cell subset is a strategy to enhance the persistence and killing capacity of CAR T cells.

It has been demonstrated that the induction of Wnt $/ \beta$ catenin signaling using inhibitors of glycogen synthase kinase $3 \beta$ (GSK-3 $\beta$ ), such as TWS119, helps to enrich $\mathrm{T}_{\mathrm{SCM}}$ cells by inhibiting differentiation in both mice and humans $[98,99]$. Karolina Pilipow et al proved that adding antioxidants, especially $\mathrm{N}$-acetylcysteine (NAC), to the manufacturing procedure for CD19 CAR T cells inhibited effector differentiation while enabling expansion of $\mathrm{CD}^{+} \mathrm{T}_{\mathrm{SCM}}$ cells and stem cell-like $\mathrm{CD}^{+} \mathrm{T}$ cells [100]. Therefore, the $\mathrm{T}_{\mathrm{SCM}}$ cell subset is the best choice for manufacturing CAR $\mathrm{T}$ cell products.

\section{The immune response decreases with the expression of humanized scFv in CAR T cells}

In several basic research experiments, humanized CAR T cells were designed and manufactured with optimized murine $\mathrm{scFv}$ fragments, and the effects were evaluated in cells or mice. It was demonstrated that humanized CAR T cells exhibit an antitumor ability similar to that of murine CAR $T$ cells with much lower immunogenicity and enhanced persistence [101-103]. Moreover, humanized CAR $\mathrm{T}$ cells will not lead to CAR $\mathrm{T}$ cell exhaustion because of the lack of tonic signaling and the ability to receive multiple stimuli from $\mathrm{CD} 19^{+}$tumor cells $[102,103]$. 


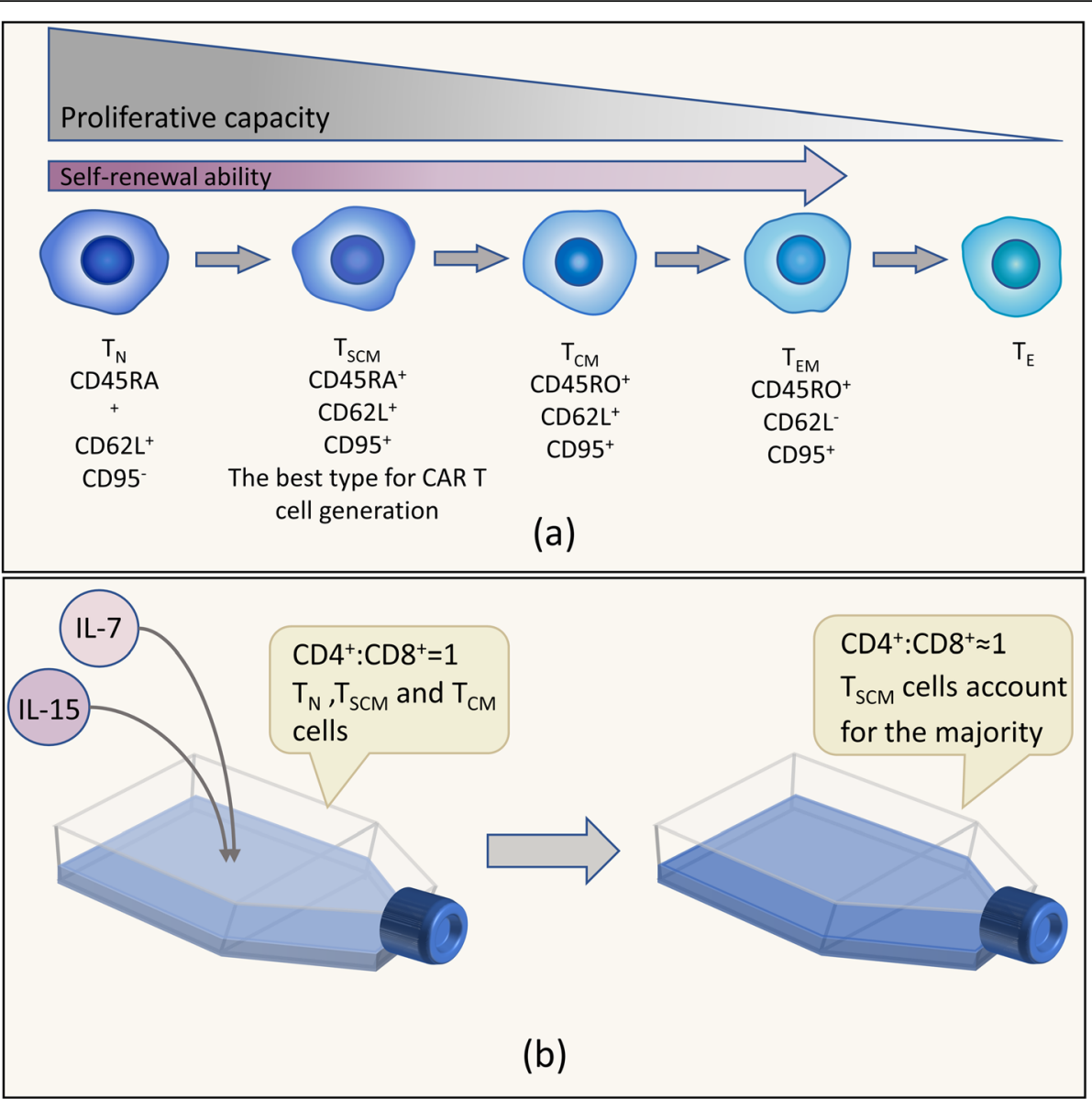

Fig. 4. Some key points during the process of manufacturing CAR T cells. a The progress of $T$ cells with the associated characteristics. As $T_{N}$ cells differentiate, the proliferative capacity of $T$ cells is gradually reduced. Except for $T_{E}$ cells, the remaining subsets have a self-renewal ability, which declines from $T_{N}$ to $T_{E M}$ cells. Therefore, it is best to choose $T_{S C M}$ cells for CAR T cell generation. b Adding IL-7/IL-15 during in vitro expansion has a positive impact. IL-7/IL-15 can increase the proportion of $\mathrm{T}_{\mathrm{SCM}}$ cells and contribute to maintaining the ratio of $\mathrm{CD} 4^{+}: \mathrm{CD} 8^{+}$cells.

In addition to studying scFvs, a study transformed hinge and transmembrane domains into humanderived versions and compared CARs with CD28 costimulatory moieties along with hinge and transmembrane domains from either the human CD28 molecule or the human CD8 $\alpha$ molecule. It has been proven that $\mathrm{T}$ cells expressing CARs with the CD8a hinge and transmembrane domains (Hu19-CD828Z) can bear multiple $\mathrm{CD} 19^{+}$cell stimulations and exhibit reduced levels of activation-induced cell death (AICD). In addition, the study found that the engineered $\mathrm{T}$ cells expressed reduced levels of PD-1 and LAG-3 so these cells could be preserved for a relatively long time. The authors found that $\mathrm{T}$ cells expressing Hu19-CD828Z had good antitumor activity with reduced cytokine production [101].

In addition, some clinical studies have confirmed that humanized CAR $\mathrm{T}$ cells can produce good antitumor effects on patients, both new patients and highly treated patients [104-106]. In particular, for those patients who experienced disease relapse after murine CAR $\mathrm{T}$ cell therapy and failed reinfusion, infusion of humanized CAR $T$ cells can achieve some degree of remission or even a MRD ${ }^{-}$status [105].

The current limitation is that the generation of a fully human-derived CAR is difficult to accomplish even if all segments of the CAR are humanized. For example, amino acid sequences not naturally expressed in humans may be present at junctions between the different components of the CAR, such as the linker connecting the light chain and heavy chain variable regions, and in the idiotypic epitopes of the variable regions [101]. In this regard, comprehensive testing of CAR constructs with bioinformatic tools to identify potential immunogenic sequences is available for removing or altering specific sites to prevent anti-CAR immune responses [101, 102]. 
Selection of the 4-1BB stimulatory domain is optimal In current clinical trials of CD19 CAR T cell therapy for

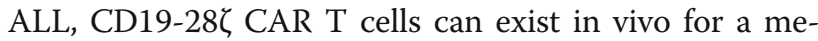
dian time of 3 months, while $68 \%$ of patients infused with $\mathrm{CD} 19-\mathrm{BB} \zeta \mathrm{CAR} \mathrm{T}$ cells exhibit cell survival for over 6 months [11]. The median $\mathrm{CD}_{19^{+}}$relapse rates of $\mathrm{CD} 19-\mathrm{BB} \zeta$ and $\mathrm{CD} 19-28 \zeta$ are $16.7 \%$ and $22.7 \%$, respectively. Studies have shown that $\mathrm{CD} 19-28 \zeta \mathrm{T}$ cells lead to rapid expansion of CAR $\mathrm{T}$ cells in vivo but also to rapid cell depletion and a high recurrence rate. In contrast, $\mathrm{CD} 19-\mathrm{BB} \zeta \mathrm{T}$ cells are characterized by relatively mild in vivo cell expansion but with a longer duration and a lower recurrence rate [21]. Therefore, it would be better to use CD19-BB $\zeta$ CAR T cells. Furthermore, another study showed that the configuration utilizing two signaling domains (CD28 and $\mathrm{CD} 3 \zeta$ ) and the 4-1BB ligand provided the highest efficacy, showing balanced tumoricidal function and increased $\mathrm{T}$ cell persistence [31]. Therefore, in third-generation CAR T cells, multiple costimulatory receptor domains are added, and CD28 combined with 4-1BB may achieve both durable and powerful effects. A study has showed that the adenine base editor (ABE )editing reduced the expression of PD1 in CART-T cells by changing the coding sequence of N74 residue of PDCD1 and can enhance cytotoxic functions in vitro and in vivo [107].

\section{The ratio of $\mathrm{CD}^{+}: \mathrm{CD} 8^{+}$CAR T cells can impact product efficacy}

It is optimal that CAR $\mathrm{T}$ cell products consist of $\mathrm{CD} 4^{+}$: $\mathrm{CD}^{+} \mathrm{T}$ cells at a $1: 1$ ratio. It has been proven that the ratio of $\mathrm{CD}^{+}: \mathrm{CD}^{+} \mathrm{CAR} \mathrm{T}$ cells influences antitumor efficacy and the persistence of CAR T-cell products is best when the products are composed of $\mathrm{CD}^{+}: \mathrm{CD} 8^{+} \mathrm{T}$ cells at a $1: 1$ ratio $[17,40]$. It is feasible to sort cells before infusion to ensure that the ratio of $\mathrm{CD} 4^{+}: \mathrm{CD} 8^{+}$ CAR $T$ cells is 1:1 or expand CAR $T$ cells at a 1:1 ratio while adding IL-7/ IL-15 to maintain the ratio [108].

\section{During expansion of CAR T cells, addition of IL-7 and IL- 15 improves the persistence and activity of CAR T cells} Several in vitro experiments have shown that IL-7 and IL-15 can induce $T_{N}$ cells to expand into memory $T$ cell subsets and, compared with IL-2, these cytokines are beneficial for preserving the phenotype of $\mathrm{T}_{\mathrm{SCM}}$ cells [108-110]. A clinical trial showed that IL-7 and IL-15 could produce prolonged survival of CAR $\mathrm{T}$ cells exposed to repeated serial antigen stimulation [108]. Moreover, it has been demonstrated in mice that CD19 CARmodified $\mathrm{T}_{\mathrm{SCM}}$ cells facilitate efficient homing to the secondary lymphoid organs and proliferate continuously in vivo $[108,110]$. In an in vitro study, researchers confirmed that a short period of CD3/CD28 costimulation (48 $\mathrm{h}$ ) increased the percentages of $\mathrm{T}_{\mathrm{SCM}}$ cells within the
$\mathrm{CD}^{+}$and $\mathrm{CD}^{+}$subsets when the cells were cultured with IL-7/IL-15 and that adding IL-21 to the culture further increased the number of $\mathrm{T}_{\mathrm{SCM}}$ cells [111] (Fig. 4b). However, whether IL-7 and IL-21 play a positive role in expansion is controversial. A study by Darya Alizadeh et al demonstrated that IL-15 preserved the $\mathrm{T}_{\mathrm{SCM}}$ phenotype by reducing mTORC1 activity but the addition of IL-7 and/or IL-21 reduced the benefits of IL15 on the CAR $\mathrm{T}$ cell phenotype and antitumor activity [112]. Thus, this area remains to be further studied. In addition, the ratio of $\mathrm{CD}^{+}: \mathrm{CD}^{+} \mathrm{CAR} \mathrm{T}$ cells can remain stable in culture medium with added IL-7 and IL-1 $5[108]$.

\section{Using an LV can increase the persistence and expansion of CAR T cells}

Lentiviruses can transduce not only dividing cells (without nuclear membranes) but also nondividing cells (with nuclear membranes), whereas retroviruses can only transduce dividing cells [113]. Lentiviral preintegration complexes can enter the nucleus via the ATP-dependent nuclear pore complex. Cells retain greater functional potential when they are transduced in their inactive state than when transduced in their active state [64]. Because of this, LVs will have a higher probability of modifying less differentiated naive $\mathrm{T}$ cells than retroviral vectors, which will increase the persistence and chance of survival of the resulting CAR T cells.

Another study proved that the expression of BB.z.CD19 and GD2 CARs from an LV could significantly reduce cell death and restore the overall expansion of CAR T cells in vitro. Therefore, BB.z CD19 CAR $\mathrm{T}$ cells produced with LVs could lead to a significant extension in survival [53]. In addition, various clinical trials have proven that compared with that of other viral vectors, the integration pattern of LVs has significantly lower risks of carcinogenic transformation and random transgenic integration [65]. Therefore, it would be better use LVs.

\section{Increased persistence of CAR T cells mediated by regulating signaling pathways $B C R$-mediated signaling pathways}

The PI3K/AKT/mTOR pathway is a BCR-mediated signaling pathway. Treatment with PI3K inhibitors during CAR $\mathrm{T}$ cell in vitro amplification can increase TN/ TSCM and TCM cell numbers [32, 68]. In addition, it can not only significantly decrease the expression of PD1 and Tim-3 but also mediate increased expression of the lymphoid homing marker CD62L [114]. In conclusion, induction with inhibitors during in vitro amplification can improve the persistence, antitumor effect and in vivo amplification of CAR T cells. 


\section{The TRAIL apoptotic pathway}

CD19 CAR Transduced primary human CTLs kill CD19 human non-Hodgkin lymphomas (NHLs) mainly via the TRAIL apoptotic pathway [69]. Because histone deacetylase inhibitors (HDACis) can upregulate the expression of DR5 in the TRAIL pathway, they can sensitize the pathway to promote tumor apoptosis. Furthermore, HDACis also reduce the expression of antiapoptotic proteins such as Bcl [70].

\section{The CGAS-STING pathway}

In the cGAS-STING pathway, the downstream molecule type I IFN has various immunostimulatory functions, which can improve the cytotoxic effect of T cells or NK cells and prevent apoptosis in effector T cells. Therefore, a cGAS-STING agonist can be used as a sensitizer of CAR T cells [71].

\section{The A2ARs pathway}

Tumor cells produce adenosine, which inhibits the antitumor ability of endogenous $\mathrm{T}$ cells through activation of the A2ARs pathway [72]. Therefore, an A2AR antagonist or shRNA targeting the A2AR gene can be used to reverse this problem and improve CAR $\mathrm{T}$ cell efficacy. The effectiveness of this approach can be improved by combination with pd-1 inhibitors $[115,116]$.

\section{Strategies focused on the BM microenvironment}

Antibodies targeting Tregs, fludarabine and cyclophosphamide can reduce the number of Tregs and augment the efficiency of CAR T cells. Before starting CAR T cell therapy, lymphodepletion in patients using fludarabine and/or cyclophosphamide decreases the number of circulating $\mathrm{T}$ cells, including Tregs, and thereby induces the proliferation of transferred $\mathrm{T}$ cells by reducing competition for IL-7 and IL-15, which support the proliferation of preexisting $\mathrm{T}$ cells $[88,117]$. $\mathrm{T}$ cells with a

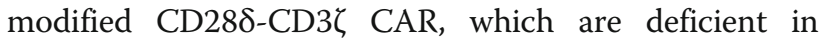
CAR-induced IL-2 secretion, reduce Treg numbers [73, 117, 118].

Retinoids and all-trans retinoic acid have been shown to diminish the suppressive effects of MDSCs, and coadministration of these molecules may enhance the efficacy of CAR therapies [77, 119]. Gene-modified NK cells bearing a chimeric receptor with the activating receptor NKG2 can kill autologous intratumoral MDSCs [120].

Suppressing the function of CSF-1 may be a great measure for reducing recurrence as CSF-1 plays a role in recruiting M2 macrophages. Zhang P. et al .[83] designed CAR $\mathrm{T}$ and CAR-NK cells targeting CSF1R to block the promotive effect of CSF-1 on M2 macrophages and obtained results indicating efficacy. Also, Antibodies targeting CD47 on the macrophage cell surface can reduce the suppression of BM microenvironment [1].
With the development of knowledge on CTLA-4, antibodies targeting CTLA-4, such as ipilimumab, have been studied in experiments to augment the effect of CAR T cells. The antitumor mechanisms of anti-CTLA-4 antibodies primarily include the following two effects: (1) modulation of tumor-specific immune effector cells, for instance, affecting $\mathrm{CD} 8^{+} \mathrm{T}$ cells to promote clonal proliferation and (2) removal of Tregs to relieve the inhibition of the tumor-directed immune response [81].

Blocking the PD-1/PD-L1 signaling pathway is expected to restore the function of effector $\mathrm{CD} 8^{+} \mathrm{T}$ cells while suppressing the functions of Tregs and MDSCs, accordingly enhancing the antitumor effect of the immune system [81]. In a phase I/II study, relapsed/refractory (RR)-AML patients with poor risk features were treated with the anti-PD-1 antibody nivolumab and azacitidine every 4-5 weeks indefinitely. Eighteen percent of the patients achieved complete remission/complete remission with incomplete blood count recovery with a median overall survival (OS) time of 9.3 months [86]. In addition, the adenine base editor reduces PD-1 by changing the glycosylated residue in CAR-T cells, which could be used to augment CAR-T therapy [107]. In terms of the structure of CAR, a PD-1-CD28 fusion receptor is able to switch original inhibitory signals into activation signal and enhance cytokine release, proliferation, and cytotoxicity of CAR-T cells [121].

IDO-1 inhibition restricts Tregs in the tumor microenvironment [88]. Indoximod (1-methyl-D-tryptophan, 1MT, NLG-8189) is the most widely studied IDO1 inhibitor, and the combination of IDO1 inhibitors and conventional therapy has shown satisfactory results in several trials.

\section{Bridging allo-HSCT after CAR T cell therapy can improve patient survival}

Brentjens et al. reported four patients who were treated with CAR T cells followed by allo-HSCT [19]. Three patients had no significant complications and remained in MRD-negative complete remission from 3 to 6 months after allo-HSCT. However, one patient who was ineligible for allo-HSCT relapsed 3 months after CAR T cell treatment. Maude et al. reported that three patients in remission were treated with CAR $\mathrm{T}$ cells followed by allo-HSCT and remained in remission for 7-12 months after CAR $\mathrm{T}$ cell treatmen $\mathrm{t}[17]$. In one study, a total of 14 patients with RR-B-ALL were treated with CD19 CAR T cells. Among the patients, seven were treated with autologous CAR $\mathrm{T}$ cells, and seven were treated with cells from donors. Eight patients achieved complete remission, but three of these patients relapsed within 3 months (Zhang $\mathrm{C}$ et al., unpublished Data). Notably, we treated a B-ALL patient with central nervous system (CNS) recurrence. After treatment with CAR T cells, the 
patient remains negative for CNS leukemia. Only one patient died on day 10 [122]. Some researchers have shown that CAR $\mathrm{T}$ cell treatment with allo-HSCT may be the best way to treat RR-B cell malignancies. Zhang et al. showed that patients with RR-B cell malignancies showed no sign of relapse at their last follow-up examination if they received CAR $\mathrm{T}$ cell treatment followed by allo-HSCT [123]. Another study showed that with a median follow-up period of 28.4 months after allogeneic HCT, the 2year Kaplan-Meier point estimates of event-free survival (EFS) and OS were $61 \%$ and $72 \%$, respectively. The 2 -year cumulative incidence of relapse (CIR) was 17\% (all with CD19-positive disease at relapse), and nonrelapse mortality (NRM) was 23\%. The authors evaluated the effect of allogeneic HCT after CAR T cell therapy on EFS as a timedependent covariate. In univariate analysis, allogeneic HCT after CAR T cell therapy was associated with longer EFS than not undergoing allogeneic HCT [35]. In a clinical trial performed by Tu SF et al., among the eight patients who underwent HSCT, only two patients relapsed, one at 100 days and one at 226 days post-HSCT. Both patients had experienced secondary relapse and had a relatively high disease burden before CAR T-cell infusion. Patients who underwent HSCT after CAR T cell infusion tended to have better disease-free survival (DFS) and OS than patients who were only observed for follow-up; however, statistical significance was not achieved $(\mathrm{P}=0.23, \mathrm{P}=0.20)$ [124].

Therefore, the best way to treat RR-ALL may be to bridge with allo-HSCT after CAR T cell therapy to improve patient survival [125].

\section{Dual-target CAR-T cells infusion can prevent antigen escape}

Except for CD19, CD22 is widely expressed in B cells and most B-ALL cells as well [126]. So, CD19/CD22 bispecific CAR-T cells can be used to prevent CD19negative relapse [91]. Because this paper mainly discusses CD19-positive ALL relapse, there will not be much discussion on dual-target CAR-T cells infusion.

\section{Conclusion}

CD19 CAR T cell therapy is an emerging method of immunotherapy for ALL treatment. However, with the increasing number of trials, $\mathrm{CD} 19^{+}$relapse has been noticed and hinders the development of this therapy. Thus, we discussed the mechanism underlying $\mathrm{CD} 19^{+}$ relapse and found that factors exist during the production of CAR T cells, such as poor-quality $\mathrm{T}$ cells, use of murine scFvs, use of the costimulatory domain of 4-1BB, and use of viral vectors. Moreover, aberrant signal transduction pathways can lead to relapse via IL-6/JAK/ STAT3 signaling and downregulated DR-5 expression and cGAS-STING signaling, for example. In addition, the roles of immunosuppressive regulatory cells and checkpoints in the BM microenvironment cannot be ignored. We also provided some strategies according to what we found. We believe that analyzing the mechanisms of $\mathrm{CD} 19^{+}$relapse can promote progress in $\mathrm{CD} 19$ CAR T cell therapy.

\begin{abstract}
Abbreviations
CAR: Chimeric antigen receptor; ALL: Acute lymphoblastic leukemia; CRS: Cytokine release syndrome; HSCT: Hematopoietic stem cell transplantation; Ph+: Philadelphia chromosome-positive; scFv: Single-chain variable fragment; $T_{C M}$ cells: Central memory $T_{;} T_{S C M}: T$ memory stem cell; $T_{N}$ : Naiive T cells; $T_{E M}$ : Effector memory T cells; $T_{E}$ : Effector T cells; TRAF2: Tumor necrosis factor receptor-associated factor 2; ICAM1: Intracellular adhesion molecule 1; ORR: Overall response rate; CTL: Cytotoxic T lymphocyte; SB: Sleeping beauty; TRAlL: Tumor necrosis factor-related apoptosis-inducing ligand; Treg: Regulatory T cell; CTLA4: Cytotoxic T-lymphocyte-associated protein 4; MDSC: Myeloid-derived suppressor cell; NKG2D: Natural killer group 2D; TAM: Tumor-associated macrophage; iTregs: Induced Tregs; GSK-3 3 : Glycogen synthase kinase $3 \beta$; NAC: N-acetylcysteine; AICD: Activation-induced cell death; NK: Natural killer cells; AML: Acute myelocytic leukemia
\end{abstract}

\section{Acknowledgments}

Not applicable.

\section{Authors' contributions}

YN, WL, DC and HT collected the clinical data, wrote the paper and drew the figures; YN, WL and DC analyzed the clinical data and drew the table; XZ and $M L$ searched papers; and ST and YL provided guidance for article writing. YN, WL and DC contributed equally to this work. All authors read and approved the final manuscript.

\section{Funding}

This work was supported by research funds from the Natural Science Foundation of Guangdong Province, China (No. 2018B03031 1042); the Science and Technology Planning Project of Guangdong Province, China (No. 2017A020215183); the Major Program for Health Medical Collaborative Innovation of Guangzhou, China (No. 201704020216); the Frontier Research Program of Guangzhou Regenerative Medicine and Health Guangdong Laboratory, China (No. 2018GZR110105014); and the Startup Project for Clinical Trials of Southern Medical University, China (No. LC2016ZD027)

\section{Availability of data and materials}

All data generated or analyzed during this study are included in this published article [and its supplementary information files].

Ethics approval and consent to participate

Not applicable.

Consent for publication

Not applicable.

\section{Competing interests}

The authors declare that they have no conflicts of interest.

\section{Author details}

${ }^{1}$ Second Clinical Medical College, Southern Medical University, No. 253, Industrial Avenue, Guangzhou, Guangdong Province, China. ${ }^{2}$ Department of Hematology, Zhujiang Hospital, Southern Medical University, No. 253, Industrial Avenue, Guangzhou, Guangdong Province, China.

Received: 11 February 2020 Accepted: 18 May 2020

Published online: 27 May 2020

\section{References}

1. Liu D. CAR-T "the living drugs", immune checkpoint inhibitors, and precision medicine: a new era of cancer therapy. J Hematol Oncol. 2019;12(1):113.

2. Hartmann J, Schussler-Lenz M, Bondanza A, Buchholz CJ. Clinical development of CAR T cells-challenges and opportunities in translating innovative treatment concepts. EMBO Mol Med. 2017;9(9):1183-97. 
3. June $\mathrm{CH}$, O'Connor RS, Kawalekar OU, Ghassemi S, Milone MC. CAR T cell immunotherapy for human cancer. Science. 2018;359(6382):1361-5.

4. Grupp SA, Kalos M, Barrett D, Aplenc R, Porter DL, Rheingold SR, et al. Chimeric antigen receptor-modified T cells for acute lymphoid leukemia. N Engl J Med. 2013;368(16):1509-18.

5. Rosenbaum L. Tragedy, Perseverance, and Chance - The Story of CAR-T Therapy. N Engl J Med. 2017;377(14):1313-5.

6. Maude SL, Laetsch TW, Buechner J, Rives S, Boyer M, Bittencourt H, et al. Tisagenlecleucel in Children and Young Adults with B-Cell Lymphoblastic Leukemia. N Engl J Med. 2018;378(5):439-48.

7. Gardner RA, Finney O, Annesley C, Brakke H, Summers C, Leger K, et al. Intent-to-treat leukemia remission by CD19 CAR T cells of defined formulation and dose in children and young adults. Blood. 2017;129(25): 3322-31.

8. Davila ML, Riviere I, Wang X, Bartido S, Park J, Curran K, et al. Efficacy and toxicity management of 19-28z CAR T cell therapy in B cell acute lymphoblastic leukemia. Sci Transl Med. 2014;6(224):224r-5r.

9. Lee DW, Kochenderfer JN, Stetler-Stevenson M, Cui YK, Delbrook C, Feldman SA, et al. T cells expressing CD19 chimeric antigen receptors for acute lymphoblastic leukaemia in children and young adults: a phase 1 doseescalation trial. Lancet. 2015;385(9967):517-28.

10. Lee DW, Gardner R, Porter DL, Louis CU, Ahmed N, Jensen M, et al. Current concepts in the diagnosis and management of cytokine release syndrome. Blood. 2014;124(2):188-95.

11. Maude SL, Frey N, Shaw PA, Aplenc R, Barrett DM, Bunin NJ, et al. Chimeric Antigen Receptor T Cells for Sustained Remissions in Leukemia. New Engl J Med. 2014;371(16):1507-17.

12. Park JH, Riviere I, Gonen M, Wang X, Senechal B, Curran KJ, et al. Long-Term Follow-up of CD19 CAR Therapy in Acute Lymphoblastic Leukemia. N Engl J Med. 2018:378(5):449-59.

13. Wang J, Hu Y, Huang $\mathrm{H}$. Acute lymphoblastic leukemia relapse after CD19targeted chimeric antigen receptor T cell therapy. J Leukocyte Biol. 2017; 102(6):1347-56.

14. Shah NN, Fry TJ. Mechanisms of resistance to CAR T cell therapy. Nat Rev Clin Oncol. 2019;16(6):372-85.

15. Majzner RG, Mackall CL. Tumor Antigen Escape from CAR T-cell Therapy. Cancer Discov. 2018;8(10):1219-26.

16. Jacoby E, Bielorai B, Avigdor A, Itzhaki O, Hutt D, Nussboim V, et al. Locally produced CD19 CAR T cells leading to clinical remissions in medullary and extramedullary relapsed acute lymphoblastic leukemia. Am J Hematol. 2018; 93(12):1485-92.

17. Turtle CJ, Hanafi LA, Berger C, Gooley TA, Cherian S, Hudecek M, et al. CD19 CAR-T cells of defined CD4+:CD8+ composition in adult B cell ALL patients. J Clin Invest. 2016;126(6):2123-38.

18. Mueller KT, Maude SL, Porter DL, Frey N, Wood P, Han X, et al. Cellular kinetics of CTL019 in relapsed/refractory B-cell acute lymphoblastic leukemia and chronic lymphocytic leukemia. Blood. 2017;130(21):2317-25.

19. Brentjens RJ, Davila ML, Riviere I, Park J, Wang X, Cowell LG, et al. CD19targeted $T$ cells rapidly induce molecular remissions in adults with chemotherapy-refractory acute lymphoblastic leukemia. Sci Transl Med. 2013;5(177):138r-77r

20. Li S, Zhang J, Wang M, Fu G, Li Y, Pei L, et al. Treatment of acute lymphoblastic leukaemia with the second generation of CD19 CAR-T containing either CD28 or 4-1BB. Br J Haematol. 2018;181(3):360-71.

21. Long AH, Haso WM, Shern JF, Wanhainen KM, Murgai M, Ingaramo M, et al. 4-1BB costimulation ameliorates T cell exhaustion induced by tonic signaling of chimeric antigen receptors. Nat Med. 2015;21(6):581-90

22. Milone MC, Fish JD, Carpenito C, Carroll RG, Binder GK, Teachey D, et al. Chimeric receptors containing CD137 signal transduction domains mediate enhanced survival of T cells and increased antileukemic efficacy in vivo. Mol Ther. 2009;17(8):1453-64

23. Kebriaei P, Singh H, Huls MH, Figliola MJ, Bassett R, Olivares $S$, et al. Phase trials using Sleeping Beauty to generate CD19-specific CAR T cells. J Clin Invest. 2016:126(9):3363-76

24. Cheng Z, Wei R, Ma Q, Shi L, He F, Shi Z, et al. In Vivo Expansion and Antitumor Activity of Coinfused CD28- and 4-1BB-Engineered CAR-T Cells in Patients with B Cell Leukemia. Mol Ther. 2018;26(4):976-85.

25. Brentjens RJ, Rivière I, Park JH, Davila ML, Wang X, Stefanski J, et al. Safety and persistence of adoptively transferred autologous CD19-targeted T cells in patients with relapsed or chemotherapy refractory B-cell leukemias. Blood. 2011;118(18):4817-28.
26. Kalos M, Levine BL, Porter DL, Katz S, Grupp SA, Bagg A, et al. T cells with chimeric antigen receptors have potent antitumor effects and can establish memory in patients with advanced leukemia. Sci Transl Med. 2011;3(95):73r-95r.

27. Norelli M, Camisa B, Barbiera G, Falcone L, Purevdorj A, Genua M, et al. Monocyte-derived IL-1 and IL- 6 are differentially required for cytokinerelease syndrome and neurotoxicity due to CAR T cells. Nat Med. 2018;24(6): $739-48$.

28. Jain N, Roberts KG, Jabbour E, Patel K, Eterovic AK, Chen K, et al. Ph-like acute lymphoblastic leukemia: a high-risk subtype in adults. Blood. 2017; 129(5):572-81.

29. Chiaretti S, Messina M, Foà R. BCR/ABL1-like acute lymphoblastic leukemia: How to diagnose and treat? Cancer-Am Cancer Soc. 2019;125(2):194-204.

30. Roberts KG, Li Y, Payne-Turner D, Harvey RC, Yang Y, Pei D, et al. Targetable kinase-activating lesions in Ph-like acute lymphoblastic leukemia. N Engl J Med. 2014:371(11):1005-15.

31. Zhao Z, Condomines M, van der Stegen S, Perna F, Kloss CC, Gunset G, et al. Structural Design of Engineered Costimulation Determines Tumor Rejection Kinetics and Persistence of CAR T Cells. Cancer Cell. 2015;28(4): $415-28$.

32. Zheng W, O'Hear CE, Alli R, Basham JH, Abdelsamed HA, Palmer LE, et al. PI3K orchestration of the in vivo persistence of chimeric antigen receptormodified T cells. Leukemia. 2018;32(5):1157-67.

33. Johnson DE, O'Keefe RA, Grandis JR. Targeting the IL-6/JAK/STAT3 signalling axis in cancer. Nat Rev Clin Oncol. 2018;15(4):234-48.

34. Holmfeldt L, Wei L, Diaz-Flores E, Walsh M, Zhang J, Ding L, et al. The genomic landscape of hypodiploid acute lymphoblastic leukemia. Nat Genet. 2013;45(3):242-52.

35. Hay KA, Gauthier J, Hirayama AV, Voutsinas JM, Wu Q, Li D, et al. Factors associated with durable EFS in adult B-cell ALL patients achieving MRDnegative CR after CD19 CAR T-cell therapy. Blood. 2019;133(15):1652-63.

36. Hu Y, Wu Z, Luo Y, Shi J, Yu J, Pu C, et al. Potent Anti-leukemia Activities of Chimeric Antigen Receptor-Modified T Cells against CD19 in Chinese Patients with Relapsed/Refractory Acute Lymphocytic Leukemia. Clin Cancer Res. 2017:23(13):3297-306.

37. Tu S, Huang R, Guo Z, Deng L, Song C, Zhou X, et al. Shortening the ex vivo culture of CD19-specific CAR T-cells retains potent efficacy against acute lymphoblastic leukemia without CAR T-cell-related encephalopathy syndrome or severe cytokine release syndrome. Am J Hematol. 2019;94(12): E322-E325.

38. Singh N, Perazzelli J, Grupp SA, Barrett DM. Early memory phenotypes drive T cell proliferation in patients with pediatric malignancies. Sci Transl Med. 2016;8(320):320r-3r

39. Printz C. Effectiveness of chimeric antigen receptor $\mathrm{T}$ cells may be impaired by prior chemotherapy. Cancer-Am Cancer Soc. 2018;124(14):2877.

40. Sommermeyer D, Hudecek M, Kosasih PL, Gogishvili T, Maloney DG, Turtle CJ, et al. Chimeric antigen receptor-modified T cells derived from defined CD8+ and CD4+ subsets confer superior antitumor reactivity in vivo. Leukemia. 2016;30(2):492-500.

41. Gattinoni L, Lugli E, Ji Y, Pos Z, Paulos CM, Quigley MF, et al. A human memory T cell subset with stem cell-like properties. Nat Med. 2011;17(10): 1290-7.

42. Sabatino M, Hu J, Sommariva M, Gautam S, Fellowes V, Hocker JD, et al. Generation of clinical-grade CD19-specific CAR-modified CD8+ memory stem cells for the treatment of human B-cell malignancies. Blood. 2016; 128(4):519-28.

43. Fraietta JA, Lacey SF, Orlando EJ, Pruteanu-Malinici I, Gohil M, Lundh S, et al. Determinants of response and resistance to CD19 chimeric antigen receptor (CAR) T cell therapy of chronic lymphocytic leukemia. Nat Med. 2018;24(5): $563-71$.

44. Maus MV, Haas AR, Beatty GL, Albelda SM, Levine BL, Liu X, et al. T cells expressing chimeric antigen receptors can cause anaphylaxis in humans. Cancer Immunol Res. 2013;1(1):26-31.

45. Lamers $\mathrm{CH}$, Willemsen $\mathrm{R}$, van Elzakker $\mathrm{P}$, van Steenbergen-Langeveld $\mathrm{S}$, Broertjes M, Oosterwijk-Wakka J, et al. Immune responses to transgene and retroviral vector in patients treated with ex vivo-engineered T cells. Blood. 2011;117(1):72-82.

46. Jensen MC, Popplewell L, Cooper LJ, DiGiusto D, Kalos M, Ostberg JR, et al. Antitransgene rejection responses contribute to attenuated persistence of adoptively transferred CD20/CD19-specific chimeric antigen receptor redirected T cells in humans. Biol Blood Marrow Transplant. 2010;16(9): $1245-56$. 
47. Kershaw MH, Westwood JA, Parker LL, Wang G, Eshhar Z, Mavroukakis SA, et al. A phase I study on adoptive immunotherapy using gene-modified T cells for ovarian cancer. Clin Cancer Res. 2006;12(20 Pt 1):6106-15.

48. Loskog A, Giandomenico V, Rossig C, Pule M, Dotti G, Brenner MK. Addition of the CD28 signaling domain to chimeric T-cell receptors enhances chimeric Tcell resistance to T regulatory cells. Leukemia. 2006;20(10):1819-28.

49. Kane LP, Lin J, Weiss A. It's all Rel-ative: NF-kappaB and CD28 costimulation of T-cell activation. Trends Immunol. 2002;23(8):413-20.

50. Kawalekar OU, O'Connor RS, Fraietta JA, Guo L, McGettigan SE, Posey AJ, et al. Distinct Signaling of Coreceptors Regulates Specific Metabolism Pathways and Impacts Memory Development in CAR T Cells. Immunity. 2016:44(2):380-90.

51. van der Windt GJ, O'Sullivan D, Everts B, Huang SC, Buck MD, Curtis JD, et al. CD8 memory T cells have a bioenergetic advantage that underlies their rapid recall ability. Proc Natl Acad Sci U S A. 2013;110(35):14336-41.

52. Mamonkin M, Mukherjee M, Srinivasan M, Sharma S, Gomes-Silva D, Mo F, et al. Reversible Transgene Expression Reduces Fratricide and Permits 4-1BB Costimulation of CAR T Cells Directed to T-cell Malignancies. Cancer Immunol Res. 2018:6(1):47-58.

53. Gomes-Silva D, Mukherjee M, Srinivasan M, Krenciute G, Dakhova O, Zheng $Y$, et al. Tonic 4-1BB Costimulation in Chimeric Antigen Receptors Impedes T Cell Survival and Is Vector-Dependent. Cell Rep. 2017;21(1):17-26.

54. Guedan S, Posey AJ, Shaw C, Wing A, Da T, Patel PR, et al. Enhancing CAR T cell persistence through ICOS and 4-1BB costimulation. JCI Insight. 2018;3(1): e96976.

55. Hombach AA, Heiders J, Foppe M, Chmielewski M, Abken H. OX40 costimulation by a chimeric antigen receptor abrogates CD28 and IL-2 induced IL-10 secretion by redirected CD4(+) T cells. Oncoimmunology. 2012;1(4):458-66.

56. Ramzi M, Khalafi-Nezhad A, Iravani Saadi M, Jowkar Z. Association between TLR2 and TLR4 Expression and Response to Induction Therapy in Acute Myeloid Leukemia Patients. Int J Hematol Oncol Stem Cell Res. 2018;12(4): 303-12

57. Kintz H, Nylen E, Barber A. Inclusion of Dap10 or 4-1BB costimulation domains in the chPD1 receptor enhances anti-tumor efficacy of T cells in murine models of lymphoma and melanoma. Cell Immunol. 2020;351: 104069.

58. Xu Y, Liu Q, Zhong M, Wang Z, Chen Z, Zhang Y, et al. 2B4 costimulatory domain enhancing cytotoxic ability of anti-CD5 chimeric antigen receptor engineered natural killer cells against T cell malignancies. J Hematol Oncol. 2019;12(1):49.

59. Golubovskaya VM, Berahovich R, Xu Q, Zhou H, Xu S, Guan J, et al. GITR domain inside CAR co-stimulates activity of CAR-T cells against cancer. Front Biosci (Landmark edition). 2018;23:2245-54.

60. Howie D, Simarro M, Sayos J, Guirado M, Sancho J, Terhorst C. Molecular dissection of the signaling and costimulatory functions of CD150 (SLAM): CD150/SAP binding and CD150-mediated costimulation. Blood. 2002;99(3): 957-65

61. Prasad DVR, Parekh W, Joshi BN, Banerjee PP, Parab PB, Chattopadhyay S, et al. The Th1-specific costimulatory molecule, m150, is a posttranslational isoform of lysosome-associated membrane protein-1. J Immunol (Baltimore, Md. : 1950). 2002;169(4):1801-9.

62. Pipkin ME, Sacks JA, Cruz-Guilloty F, Lichtenheld MG, Bevan MJ, Rao A Interleukin-2 and inflammation induce distinct transcriptional programs that promote the differentiation of effector cytolytic T cells. Immunity. 2010; 32(1):79-90.

63. Yu WL, Hua ZC. Chimeric Antigen Receptor T-cell (CAR T) Therapy for Hematologic and Solid Malignancies: Efficacy and Safety-A Systematic Review with Meta-Analysis. Cancers (Basel). 2019;11(1):47.

64. Milone MC, O'Doherty U. Clinical use of lentiviral vectors. Leukemia. 2018; 32(7):1529-41.

65. Poorebrahim M, Sadeghi S, Fakhr E, Abazari MF, Poortahmasebi V, Kheirollahi A, et al. Production of CAR T-cells by GMP-grade lentiviral vectors: latest advances and future prospects. Crit Rev Clin Lab Sci. 2019; 56(6):393-419

66. Beatty GL, Haas AR, Maus MV, Torigian DA, Soulen MC, Plesa G, et al Mesothelin-specific chimeric antigen receptor mRNA-engineered T cells induce anti-tumor activity in solid malignancies. Cancer Immunol Res. 2014; 2(2):112-20

67. Ren J, Zhao Y. Advancing chimeric antigen receptor T cell therapy with CRISPR/Cas9. Protein Cell. 2017;8(9):634-43.
68. Urak R, Walter M, Lim L, Wong CW, Budde LE, Thomas S, et al. Ex vivo Akt inhibition promotes the generation of potent CD19CAR T cells for adoptive immunotherapy. J Immunother Cancer. 2017;5:26.

69. Torres-Collado AX, Jazirehi AR. Overcoming Resistance of Human NonHodgkin's Lymphoma to CD19-CAR CTL Therapy by Celecoxib and Histone Deacetylase Inhibitors. Cancers (Basel). 2018;10(6):200.

70. Nakata S, Yoshida T, Horinaka M, Shiraishi T, Wakada M, Sakai T. Histone deacetylase inhibitors upregulate death receptor 5/TRAIL-R2 and sensitize apoptosis induced by TRAIL/APO2-L in human malignant tumor cells. Oncogene. 2004;23(37):6261-71.

71. Li A, Yi M, Qin S, Song Y, Chu Q, Wu K. Activating CGAS-STING pathway for the optimal effect of cancer immunotherapy. J Hematol Oncol. 2019;12(1):35.

72. Ohta A, Gorelik E, Prasad SJ, Ronchese F, Lukashev D, Wong MK, et al. A2A adenosine receptor protects tumors from antitumor T cells. Proc Natl Acad Sci U S A. 2006:103(35):13132-7.

73. Kofler DM, Chmielewski M, Rappl G, Hombach AA, Hombach A, Riet T, et al. CD28 Costimulation Impairs the Efficacy of a Redirected T-cell Antitumor Attack in the Presence of Regulatory T cells Which Can Be Overcome by Preventing Lck Activation. Mol Ther. 2011;19(4):760-7.

74. Onea AS, Jazirehi AR. CD19 chimeric antigen receptor (CD19 CAR)redirected adoptive T-cell immunotherapy for the treatment of relapsed or refractory B-cell Non-Hodgkin's Lymphomas. Am J Cancer Res. 2016;6(2): 403-24.

75. Bair SM, Mato A, Svoboda J. Immunotherapy for the Treatment of Hodgkin Lymphoma: An Evolving Paradigm. Clin Lymphoma Myeloma Leuk. 2018; 18(6):380-91.

76. Abbas AK, Benoist C, Bluestone JA, Campbell DJ, Ghosh S, Hori S, et al. Regulatory $T$ cells: recommendations to simplify the nomenclature. Nat Immunol. 2013;14(4):307-8.

77. Long AH, Highfill SL, Cui Y, Smith JP, Walker AJ, Ramakrishna S, et al. Reduction of MDSCs with All-trans Retinoic Acid Improves CAR Therapy Efficacy for Sarcomas. Cancer Immunol Res. 2016;4(10):869-80.

78. Di S, Zhou M, Pan Z, Sun R, Chen M, Jiang H, et al. Combined Adjuvant of Poly I:C Improves Antitumor Effects of CAR-T Cells. Front Oncol. 2019;9:241.

79. Burga RA, Thorn M, Point GR, Guha P, Nguyen CT, Licata LA, et al. Liver myeloid-derived suppressor cells expand in response to liver metastases in mice and inhibit the anti-tumor efficacy of anti-CEA CAR-T. Cancer Immunol Immunother. 2015;64(7):817-29.

80. Guha P, Gardell J, Darpolor J, Cunetta M, Lima M, Miller G, et al. STAT3 inhibition induces Bax-dependent apoptosis in liver tumor myeloid-derived suppressor cells. Oncogene. 2019;38(4):533-48.

81. Gao S, Yang D, Fang $Y$, Lin $X$, Jin $X$, Wang Q, et al. Engineering Nanoparticles for Targeted Remodeling of the Tumor Microenvironment to Improve Cancer Immunotherapy. Theranostics. 2019;9(1):126-51.

82. Wang Z, Till B, Gao Q. Chemotherapeutic agent-mediated elimination of myeloid-derived suppressor cells. Oncoimmunology. 2017;6:e1331807.

83. Zhang P, Zhao S, Wu C, Li J, Li Z, Wen C, et al. Effects of CSF1R-targeted chimeric antigen receptor-modified NK92MI \& T cells on tumor-associated macrophages. Immunotherapy-UK. 2018;10(11):935-49.

84. Burger JA, Gribben JG. The microenvironment in chronic lymphocytic leukemia (CLL) and other B cell malignancies: insight into disease biology and new targeted therapies. Semin Cancer Biol. 2014;24:71-81.

85. Lamble AJ, Lind EF. Targeting the Immune Microenvironment in Acute Myeloid Leukemia: A Focus on T Cell Immunity. Front Oncol. 2018;8:213.

86. Liu Y, Bewersdorf JP, Stahl M, Zeidan AM. Immunotherapy in acute myeloid leukemia and myelodysplastic syndromes: The dawn of a new era? Blood Rev. 2019;34:67-83.

87. Hornyák L, Dobos N, Koncz G, Karányi Z, Páll D, Szabó Z, et al. The Role of Indoleamine-2,3-Dioxygenase in Cancer Development, Diagnostics, and Therapy. Front Immunol. 2018;9:151.

88. Irving M, Vuillefroy De Silly R, Scholten K, Dilek N, Coukos G. Engineering Chimeric Antigen Receptor T-Cells for Racing in Solid Tumors: Don't Forget the Fuel. Front Immunol. 2017:8:267.

89. Liu M, Wang X, Wang L, Ma X, Gong Z, Zhang S, et al. Targeting the IDO1 pathway in cancer: from bench to bedside. J Hematol Oncol. 2018;11(1):100.

90. Ghosh A, Smith M, James SE, Davila ML, Velardi E, Argyropoulos KV, et al. Donor CD19 CAR T cells exert potent graft-versus-lymphoma activity with diminished graft-versus-host activity. Nat Med. 2017;23(2):242-9.

91. Zhao J, Song Y, Liu D. Clinical trials of dual-target CAR T cells, donor-derived CAR T cells, and universal CAR T cells for acute lymphoid leukemia. J Hematol Oncol. 2019;12(1):17. 
92. Brudno JN, Somerville RP, Shi V, Rose JJ, Halverson DC, Fowler DH, et al. Allogeneic T Cells That Express an Anti-CD19 Chimeric Antigen Recepto Induce Remissions of B-Cell Malignancies That Progress After Allogeneic Hematopoietic Stem-Cell Transplantation Without Causing Graft-Versus-Host Disease. J Clin Oncol. 2016;34(10):1112-21.

93. Chen Y, Cheng Y, Suo P, Yan C, Wang Y, Chen Y, et al. Donor-derived CD19targeted $T$ cell infusion induces minimal residual disease-negative remission in relapsed B-cell acute lymphoblastic leukaemia with no response to donor lymphocyte infusions after haploidentical haematopoietic stem cell transplantation. Br J Haematol. 2017;179(4):598-605.

94. Kochenderfer JN, Dudley ME, Carpenter RO, Kassim SH, Rose JJ, Telford WG, et al. Donor-derived CD19-targeted T cells cause regression of malignancy persisting after allogeneic hematopoietic stem cell transplantation. Blood. 2013;122(25):4129-39.

95. Lugli E, Dominguez MH, Gattinoni L, Chattopadhyay PK, Bolton DL, Song K, et al. Superior T memory stem cell persistence supports long-lived T cell memory. J Clin Invest. 2013;123(2):594-9.

96. Li M, Yao D, Zeng X, Kasakovski D, Zhang Y, Chen S, et al. Age related human T cell subset evolution and senescence. Immun Ageing. 2019;16:24.

97. Blaeschke F, Stenger D, Kaeuferle T, Willier S, Lotfi R, Kaiser AD, et al. Induction of a central memory and stem cell memory phenotype in functionally active CD4(+) and CD8(+) CAR T cells produced in an automated good manufacturing practice system for the treatment of CD19(+) acute lymphoblastic leukemia. Cancer Immunol Immunother. 2018; 67(7):1053-66.

98. Gattinoni L, Zhong XS, Palmer DC, Ji Y, Hinrichs CS, Yu Z, et al. Wnt signaling arrests effector $T$ cell differentiation and generates CD8+ memory stem cells. Nat Med. 2009;15(7):808-13.

99. Muralidharan S, Hanley PJ, Liu E, Chakraborty R, Bollard C, Shpall E, et al. Activation of Wnt signaling arrests effector differentiation in human peripheral and cord blood-derived T lymphocytes. J Immunol. 2011;187(10): 5221-32.

100. Pilipow K, Scamardella E, Puccio S, Gautam S, De Paoli F, Mazza EM, et al. Antioxidant metabolism regulates CD8+ T memory stem cell formation and antitumor immunity. JCI Insight. 2018;3(18):e122299.

101. Alabanza L, Pegues M, Geldres C, Shi V, Wiltzius J, Sievers SA, et al. Function of Novel Anti-CD19 Chimeric Antigen Receptors with Human Variable Regions Is Affected by Hinge and Transmembrane Domains. Mol Ther. 2017; 25(11):2452-65.

102. Sommermeyer D, Hill T, Shamah SM, Salter Al, Chen Y, Mohler KM, et al. Fully human CD19-specific chimeric antigen receptors for T-cell therapy. Leukemia. 2017;31(10):2191-9.

103. Mirzaei HR, Jamali A, Jafarzadeh L, Masoumi E, Alishah K, Fallah MK, et al. Construction and functional characterization of a fully human anti-CD19 chimeric antigen receptor (huCAR)-expressing primary human T cells. J Cell Physiol. 2019;234(6):9207-15.

104. Zhao Y, Liu Z, Wang X, Wu H, Zhang J, Yang J, et al. Treatment with Humanized Selective CD19CAR-T Cells Shows Efficacy in Highly Treated BALL Patients Who Have Relapsed after Receiving Murine-Based CD19CAR-T Therapies. Clin Cancer Res. 2019;25(18):5595-607.

105. Yang F, Zhang J, Zhang X, Tian M, Wang J, Kang L, et al. Delayed remission following sequential infusion of humanized CD19- and CD22-modified CAR$T$ cells in a patient with relapsed/refractory acute lymphoblastic leukemia and prior exposure to murine-derived CD19-directed CAR-T cells. Onco Targets Ther. 2019;12:2187-91.

106. Cao J, Cheng H, Shi M, Wang G, Chen W, Qi K, et al. Humanized CD19specific chimeric antigen-receptor T-cells in 2 adults with newly diagnosed B-cell acute lymphoblastic leukemia. Leukemia. 2019;33(11):2751-3.

107. Shi $X$, Zhang D, Li F, Zhang Z, Wang S, Xuan Y, et al. Targeting glycosylation of PD-1 to enhance CAR-T cell cytotoxicity. J Hematol Oncol. 2019;12(1):127.

108. Xu Y, Zhang M, Ramos CA, Durett A, Liu E, Dakhova O, et al. Closely related T-memory stem cells correlate with in vivo expansion of CAR.CD19-T cells and are preserved by IL-7 and IL-15. Blood. 2014;123(24):3750-9.

109. Cieri N, Camisa B, Cocchiarella F, Forcato M, Oliveira G, Provasi E, et al. IL-7 and IL-15 instruct the generation of human memory stem $T$ cells from naive precursors. Blood. 2013;121(4):573-84.

110. Ali R, Babad J, Follenzi A, Gebe JA, Brehm MA, Nepom GT, et al. Genetically modified human CD4(+) T cells can be evaluated in vivo without lethal graft-versus-host disease. Immunology. 2016;148(4):339-51.

111. Alvarez-Fernández C, Escribà-Garcia L, Vidal S, Sierra J, Briones J. A short CD3/CD28 costimulation combined with IL-21 enhance the generation of human memory stem T cells for adoptive immunotherapy. J Transl Med. 2016;14(1):214.

112. Alizadeh D, Wong RA, Yang X, Wang D, Pecoraro JR, Kuo CF, et al. IL15 Enhances CAR-T Cell Antitumor Activity by Reducing mTORC1 Activity and Preserving Their Stem Cell Memory Phenotype. Cancer Immunol Res. 2019; 7(5):759-72.

113. Yuan W, Chen J, Cao Y, Yang L, Shen L, Bian Q, et al. Comparative analysis and optimization of protocols for producing recombinant lentivirus carrying the anti-Her2 chimeric antigen receptor gene. J Gene Med. 2018;20(7-8):e3027.

114. Stock S, Ubelhart R, Schubert ML, Fan F, He B, Hoffmann JM, et al. Idelalisib for optimized CD19-specific chimeric antigen receptor T cells in chronic lymphocytic leukemia patients. Int J Cancer. 2019;145(5):1312-24.

115. Beavis PA, Milenkovski N, Henderson MA, John LB, Allard B, Loi S, et al. Adenosine Receptor 2A Blockade Increases the Efficacy of Anti-PD-1 through Enhanced Antitumor T-cell Responses. Cancer Immunol Res. 2015; 3(5):506-17.

116. Beavis PA, Henderson MA, Giuffrida L, Mills JK, Sek K, Cross RS, et al. Targeting the adenosine $2 \mathrm{~A}$ receptor enhances chimeric antigen receptor $\mathrm{T}$ cell efficacy. J Clin Invest. 2017;127(3):929-41.

117. Golubovskaya V, Wu L. Different Subsets of T Cells, Memory, Effector Functions, and CAR-T Immunotherapy. Cancers. 2016;8(3):36.

118. Perna SK, Pagliara D, Mahendravada A, Liu H, Brenner MK, Savoldo B, et al. Interleukin-7 Mediates Selective Expansion of Tumor-redirected Cytotoxic T Lymphocytes (CTLs) without Enhancement of Regulatory T-cell Inhibition. Clin Cancer Res. 2014;20(1):131-9.

119. Iclozan C, Antonia S, Chiappori A, Chen DT, Gabrilovich D. Therapeutic regulation of myeloid-derived suppressor cells and immune response to cancer vaccine in patients with extensive stage small cell lung cancer. Cancer Immunol Immunother. 2013;62(5):909-18.

120. Parihar R, Rivas C, Huynh M, Omer B, Lapteva N, Metelitsa LS, et al. NK Cells Expressing a Chimeric Activating Receptor Eliminate MDSCs and Rescue Impaired CAR-T Cell Activity against Solid Tumors. Cancer Immunol Res. 2019:7(3):363-75.

121. Wei J, Han X, Bo J, Han W. Target selection for CAR-T therapy. J Hematol Oncol. 2019;12(1):62

122. Liu J, Zhang $X$, Zhong JF, Zhang C. Use of chimeric antigen receptor T cells in allogeneic hematopoietic stem cell transplantation. Immunotherapy-UK. 2019;11(1):37-44.

123. Liu J, Zhong JF, Zhang X, Zhang C. Allogeneic CD19-CAR-T cell infusion after allogeneic hematopoietic stem cell transplantation in B cell malignancies. J Hematol Oncol. 2017;10(1):35.

124. Tu S, Huang R, Deng L, Zhou X, He Y, Zhou W, et al. Therapy of 4s Chimeric Antigen Receptor T Cells Achieves Long-Term Disease-Free Survival with No Severe CRS or Cres in Patients with Relapsed and Refractory Acute Lymphoblastic Leukemia. Blood. 2018;1321(UNSP 2696):2696.

125. Liu J, Zhang X, Zhong JF, Zhang C. CAR-T cells and allogeneic hematopoietic stem cell transplantation for relapsed/refractory B-cell acute lymphoblastic leukemia. Immunotherapy-UK. 2017;9(13):1115-25.

126. Ereño-Orbea J, Sicard T, Cui H, Mazhab-Jafari MT, Benlekbir S, Guarné A, et al. Molecular basis of human CD22 function and therapeutic targeting. Nat Commun. 2017:8(1):764.

\section{Publisher's Note}

Springer Nature remains neutral with regard to jurisdictional claims in published maps and institutional affiliations.

Ready to submit your research? Choose BMC and benefit from:

- fast, convenient online submission

- thorough peer review by experienced researchers in your field

- rapid publication on acceptance

- support for research data, including large and complex data types

- gold Open Access which fosters wider collaboration and increased citations

- maximum visibility for your research: over $100 \mathrm{M}$ website views per year

At $\mathrm{BMC}$, research is always in progress.

Learn more biomedcentral.com/submissions 